$\mathcal{G}_{\text {http://dx.doi.org/10.3765/sp.7.2 }}^{\text {Semantics \& Pragmatics Volume 7, Article 2: 1-53, } 2014}$

\title{
Varieties of update*
}

\author{
Sarah E. Murray \\ Cornell University
}

Submitted 2012-10-15 / Revisions Required 2013-01-09 / Revision Received 201303-31 / Revisions Required 2013-05-02 / Revision Received 2013-07-08 / Accepted 2013-08-12 / Final Version Received 2013-08-27 / Published 2014-03-03

\begin{abstract}
This paper discusses three potential varieties of update: updates to the common ground, structuring updates, and updates that introduce discourse referents. These different types of update are used to model different aspects of natural language phenomena. Not-at-issue information directly updates the common ground. The illocutionary mood of a sentence structures the context. Other updates introduce discourse referents of various types, including propositional discourse referents for at-issue information. Distinguishing these types of update allows a unified treatment of a broad range of phenomena, including the grammatical evidentials found in Cheyenne (Algonquian) as well as English evidential parentheticals, appositives, and mood marking. An update semantics that can formalize all of these varieties of update is given, integrating the different kinds of semantic contributions into a single representation of meaning.
\end{abstract}

Keywords: update semantics, evidentials, parentheticals, appositives, mood, hedges

\section{Introduction}

Several natural language expressions seem to require an analysis that distinguishes semantic contributions further than what is asserted, what is

* For helpful comments and discussion, I am grateful to Maria Bittner, Adam Bjorndahl, Jeroen Groenendijk, Erik Hoversten, Tim Hunter, Wayne Leman, Lisa Matthewson, Eric McCready, Jessica Rett, Floris Roelofsen, Katrin Schulz, Roger Schwarzschild, William Starr, Matthew Stone, the Cornell Semantics Group, three anonymous S\&P reviewers, and audiences at Rutgers, the University of Rochester, the University of Chicago, the Workshop on Projection, Entailment, Presupposition, and Assertion II (UBC), and Evidentials Fest (OSU). I would also like to thank my Cheyenne consultants, and others I have talked with about Cheyenne, for their collaboration and discussion of Cheyenne data. Any errors are my own.

(C)2014 Sarah E. Murray

This is an open-access article distributed under the terms of a Creative Commons Attribution License (http://creativecommons.org/licenses/by/3.o/). 
presupposed, and what is implicated. In particular, there are phenomena that do not fit into our traditional categories of presupposition and implicature, that have more in common with assertion, but yet are not quite what we would like to call "asserted". Recent work on evidentials, modals, parentheticals, appositives, expressives, not-at-issue content, and illocutionary mood, has provided a variety of analyses for such phenomena (Asher 2000, Horn 2002, Faller 2002, Gunlogson 2002, Jayez \& Rossari 2004, Portner 2004, Potts 2005, Matthewson, Rullmann \& Davis 2007, Farkas \& Bruce 2010, Murray 2010, AnderBois, Brasoveanu \& Henderson 2010, Ciardelli, Groenendijk \& Roelofsen 2009, Simons et al. 2010, among many others). Many of these analyses appeal to a distinction in propositional content between what is at-issue, roughly primary or proffered, and what is not-at-issue.

Building on this work, I propose that distinguishing three varieties of semantic update allows a natural, unified analysis of these phenomena. These updates assume that a context includes a common ground, information taken for granted for the purposes of the conversation (Stalnaker 1978), and discourse referents of various types, objects under discussion that are potential antecedents for anaphora (Karttunen 1976), among others things such as questions that have been introduced and actions that are currently permissible (Lewis 1979, Ginzburg 1996, Roberts 1996, Gunlogson 2001, Portner 2004, Farkas \& Bruce 2010, Starr 2010, among many others).

The varieties of update that I consider in this paper are updates to the common ground, updates that structure the context, and updates that introduce discourse referents. Following Murray 2010, I argue all sentences contribute updates of each variety. In particular, a sentence makes at least three new semantic contributions: introducing a discourse referent for the at-issue proposition, directly adding not-at-issue information, if there is any, to the common ground, and imposing structure on the context. These contributions are in addition to any presuppositions or implicatures that might be contributed by a sentence, which I do not discuss in this paper, as well as any other types of discourse referents that might be introduced.

Several phenomena can be analyzed by making these distinctions between kinds of semantic update. For example, Cheyenne ${ }^{1}$ evidentials (1), what we might call evidential parentheticals in English slifting constructions (2),

1 Cheyenne is a Plains Algonquian language spoken in Montana and Oklahoma. Data presented are from my fieldwork with the Cheyenne, which has taken place summers since 2006 on the Northern Cheyenne Indian Reservation in Montana. This fieldwork draws on a grammar (Leman 2012), dictionary (Fisher et al. 2006), and texts (Leman 198ob, 1987). 
Varieties of update

and English appositives (3), as well as the marking of illocutionary mood (declarative, interrogative, etc.), as contributed by intonation and word order in English (4) or by an illocutionary mood marker in Cheyenne (5).

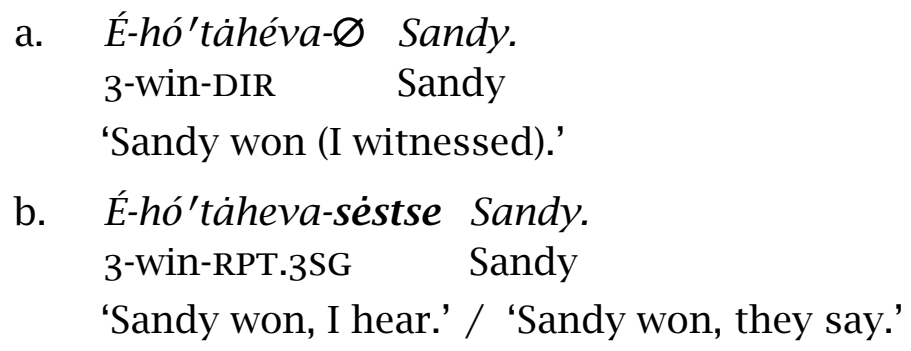

a. É-hótáhéva- $\varnothing$ Sandy. 3-win-DIR Sandy 'Sandy won (I witnessed).'

b. É-hóttäheva-sèstse Sandy. 3-win-RPT.3SG Sandy

'Sandy won, I hear.' / 'Sandy won, they say.'

(2) Floyd won the race, I hear.

(3) Tivi, who is a cat, likes to chase her tail.

(4) Did Floyd win the race?

(5) É-hó'täheva-he Sandy? 3-win-Y/N Sandy

'Did Sandy win?'

Sentences with evidentials, as in Cheyenne (1), involve two propositions: an evidential proposition and a proposition in the evidential's scope, the prejacent (e.g., Faller 2002, 2006, Matthewson, Rullmann \& Davis 2007, Murray 2010). For both (1a) and (1b), the proposition in the evidential's scope is the proposition that Sandy won. The evidential proposition for (1a) is that the speaker has direct evidence that Sandy won (e.g., the speaker witnessed the contest). For (1b), it is that the speaker has reportative evidence that Sandy won (e.g., the speaker was told or (over)heard that Sandy won the contest).

Both propositions are typically, if not always, new information - even if it is known that the speaker has some kind of evidence, for exactly what will be new. However, these two propositions have different statuses (e.g., Faller 2002, 2006, Matthewson, Rullmann \& Davis 2007, Murray 2010). Based on a variety of semantic diagnostics that test, for example, what propositions are directly challengeable and what the speaker is committed to (e.g., Simons et al. 2010, Tonhauser 2012), I conclude that the evidential proposition is not-at-issue while the proposition in the evidential's scope is at-issue (Murray 2010). For example, in Cheyenne (6), the proposition that Kathy sang is directly challengeable but the proposition that the speaker has reportative 
evidence that Kathy sang is not directly challengeable. These challenges are illustrated here by their English counterparts $(6 b)$ and $\left(6 b^{\prime}\right)$.

$$
\begin{aligned}
& \text { a. É-némene-séstse Kathy. } \\
& \text { 3-sing-RPT.3SG Kathy } \\
& \text { 'Kathy sang, I hear.' } \\
& \text { b. } \quad \checkmark N o \text {, she didn't (sing). She danced. } \\
& \text { b'. \# No, you didn't (hear that). }
\end{aligned}
$$

Parallel data hold for evidential parentheticals, such as the English translation given for Cheyenne (6a), and appositives, as in English (7), which also make not-at-issue contributions (see also, e.g., Potts 2005, AnderBois, Brasoveanu \& Henderson 2010). ${ }^{2}$

(7) a. Tivi, who is a cat, likes to chase her tail.

b. $\quad \checkmark N o$, she doesn't (like to chase her tail). She's afraid of it.

b'. \# No, she isn't (a cat).

Though the not-at-issue content is not directly challengeable, it is indirectly challengeable, e.g., Hey wait, she's not a cat! (see, e.g., Shanon 1976).

This distinction between at-issue and not-at-issue content can be captured as a distinction between information directly added to the common ground and information proposed to be added to the common ground (Murray 2009, 2010, AnderBois, Brasoveanu \& Henderson 2010). These are two of the varieties of update discussed in this paper, since I treat proposals to update the common ground as types of context structuring updates. I take the characteristic semantic contribution of a sentence's illocutionary mood (declarative, interrogative, imperative) to be a structuring update, called an illocutionary relation. Declarative mood contributes the proposal to add a

2 Related data hold for many other phenomena that we could say are, or can be, not-at-issue: certain embedding verbs (Simons 2007), expressives such as English particles like man (McCready 2008), pejoratives, and exclamations (McCready 2010), among many others. However, a distinction must be made between phenomena that can be made at-issue and phenomena that cannot be made at-issue. I argue that Cheyenne evidentials are grammatically not-at-issue (Murray 2010), but some phenomena may have variable at-issue status, such as English embedding verbs (Simons 2007, see also page 16 below) and English epistemic modals (the Mastermind example in von Fintel \& Gillies 2007). This is most likely related both to discourse structure (Simons et al. 2010) and grammatical status. 
Varieties of update

proposition to the common ground. Other moods make other structuring contributions. The polar interrogative mood in English (4) and Cheyenne (5) imposes a partition on the context, implementing Groenendijk \& Stokhof 1984 and Groenendijk 1999, setting up the possible answers, incorporating Hamblin 1973. Imperative mood can be treated as imposing a preference relation on the context, following Starr 2010.

Explicitly analyzing the semantic contribution of illocutionary mood allows an account of how evidentials and evidential parentheticals can affect the illocutionary force of an utterance of a sentence. For example, English (8), a slifting construction (Ross 1973), makes less of a commitment to the at-issue proposition that Floyd won than (9) does.

(9) Floyd won the race.

While we want to say that (9) proposes to add the at-issue proposition (that Floyd won) to the common ground, the default contribution of declarative mood, this analysis would not be appropriate for (8). Instead, what is proposed in (8) is that the at-issue proposition is at least possible. ${ }^{3}$ The evidential parenthetical in (8) is a hedge: it explicitly affects the illocutionary force of an utterance of the sentence (see, e.g., Slote 1979). Yet, though (8) is hedged, it is still a declarative sentence. Under the proposed analysis of mood, hedges can be analyzed as altering the propositional argument of the structuring update, keeping the contribution of declarative mood constant. This type of analysis allows fine-grained distinctions in the illocutionary relation of a sentence, which constrains the utterance's illocutionary force.

In some languages, sentences with reportative evidentials do not even require that the at-issue proposition is possible (see, e.g., Faller 2002, Murray 2010). In such languages, the speaker can assert the negation of the reportative's scope, showing that there is no commitment to the at-issue proposition. This is true for the reportative in Cheyenne, as exemplified in (10), where the speaker has direct eyewitness evidence to the contrary of what has been reported; the at-issue proposition in the second conjunct is the negation of the at-issue proposition from the first. ${ }^{4}$

3 This treats English (8) as parallel to reportative evidentials in languages where the speaker is committed to the at-issue proposition being at least possible (e.g., Matthewson, Rullmann \& Davis 2007).

4 Though no commitment to the at-issue proposition is required, Cheyenne speakers often use the reportative when they believe the scope proposition is true. The Cheyenne reportative 
É-hó'täheva-sèstse Sandy naa oha é-sáa-hóttàhévá-he-Ø. 3-win-RPT.3SG Sandy and CNTR 3-neg-win-MOD A-DIR $^{-}$ 'Sandy won, they say, but (I was there and) she didn't.'

Cheyenne (2), the first conjunct of (10), makes no commitment to the at-issue proposition while English (8) makes a weakened commitment to the at-issue proposition. By using structuring updates to analyze illocutionary mood and analyzing certain phenomena as affecting the propositional argument of the structuring update, such data can be accounted for (see Section 2.1).

In addition to (direct) updates to the common ground and structuring updates, the final variety of update discussed in this paper is the introduction of discourse referents of various types. This allows a further distinction between at-issue and not-at-issue content. At-issue information is always represented by a propositional discourse referent. Not-at-issue information does not automatically introduce a propositional discourse referent, or one is not easily accessible (Murray 2010). In addition to propositional discourse referents, we need referents for several other types of objects. Discourse referents for individuals, for example, can be introduced within not-at-issue content and are accessible to at-issue content, and vice versa. In general, anaphora between at-issue and not-at-issue content is robust, and must be accounted for (see Nouwen 2007, Amaral, Roberts \& Smith 2007, Murray 2010, AnderBois, Brasoveanu \& Henderson 2010, Lee 2011, among others).

Using the varieties of update distinguished above, I provide a novel, unified treatment of a range of phenomena, including evidentials, illocutionary mood, parentheticals, and appositives. These phenomena make different types of semantic contributions, all of which can be integrated into a single representation of meaning. The proposal improves the empirical coverage of existing accounts and allows a compositional analysis of the phenomena, including the interaction of mood with evidentials and hedges. The analysis leads to a typology of semantic contributions that various expressions crosslinguistically can make.

In the next section, I discuss these three varieties of update in more detail and use them to analyze the above phenomena, in pictures. The core proposal is not implementation specific and thus is illustrated independent of any particular formalization. In Section 3, a formal implementation is given, to show that all of these varieties of update can be represented in a single,

must be used if the speaker only has reportative evidence, no matter how strongly they believe the scope proposition. Parallel usage facts hold for other Cheyenne evidentials. 
Varieties of update

coherent, unidimensional system. The analysis is implemented in Update with Centering (Bittner 2009, 2011), an update semantics that represents truth-conditional information as well as anaphoric potential. In Section 4, I discuss related systems that have been introduced to analyze some of the above phenomena as well as prospects for extending the proposed analysis. Section 5 is the conclusion.

\section{Varieties of update in natural language}

The primary goal of this section is to give an informal introduction to three varieties of update: direct updates to the common ground, context structuring updates, including proposed common ground updates, and updates that introduce discourse referents. ${ }^{5}$ Distinguishing these allows for a natural analysis of a variety of phenomena. I focus on simple examples of four: grammatical evidentials in Cheyenne, mood marking in both Cheyenne and English, evidential parentheticals in English, and English appositives.

\subsection{Evidentials and illocutionary mood}

Sentences with evidentials crosslinguistically contribute both an evidential proposition and the proposition in the evidential's scope, though these propositions have different statuses (e.g., Faller 2002, 2006, Matthewson, Rullmann $\&$ Davis 2007, Murray 2010). For example, consider (11), a Cheyenne sentence with a direct evidential. The Cheyenne direct evidential is the unmarked member of the evidential paradigm and contributes the requirement that the speaker has direct (e.g., eyewitness) evidence for the proposition in the evidential's scope (Murray 2010). In (11), the proposition that Sandy won, call it $q$, is at-issue. The evidential proposition, that the speaker $(i)$ has direct evidence (DIR) that Sandy won, $\operatorname{DIR}(i, q)$, is not-at-issue.

$$
\begin{array}{ll}
\text { É-hó'tȧhéva- } \varnothing & \text { Sandy. } \\
\text { 3-win-DIR } & \text { Sandy } \\
\text { 'Sandy won (I witnessed).' }
\end{array}
$$

I analyze Cheyenne (11) as making three semantic contributions: a presentation of the at-issue proposition, a not-at-issue restriction, and an illocutionary

5 To some extent, this parallels the distinction between updates of information and attention (Bittner 2009, 2011, Groenendijk \& Roelofsen 2009, Ciardelli, Groenendijk \& Roelofsen 2009): see $§ 4$ below. 
relation. These are modeled respectively as an update introducing a discourse referent, a direct update to the common ground, and a structuring update. I take these to be part of the conventional contribution of the words and morphemes in (11) and to provide an instruction of how to update a context, encoding both truth conditions and anaphoric potential.

Figure 1 below illustrates the updates contributed by (11). The common ground is the information taken for granted for the purposes of the conversation, a set of propositions; its intersection is a set of worlds, the context set (Stalnaker 1978). I assume the initial common ground includes some information, represented by the context set $p_{0}$ in the first diagram in Figure $1 .{ }^{6}$ Gray shading represents the current context set, at each stage of update. Propositions represented by a discourse referent (abbreviated dref) are indicated with solid lines, dashed lines for propositions without one.

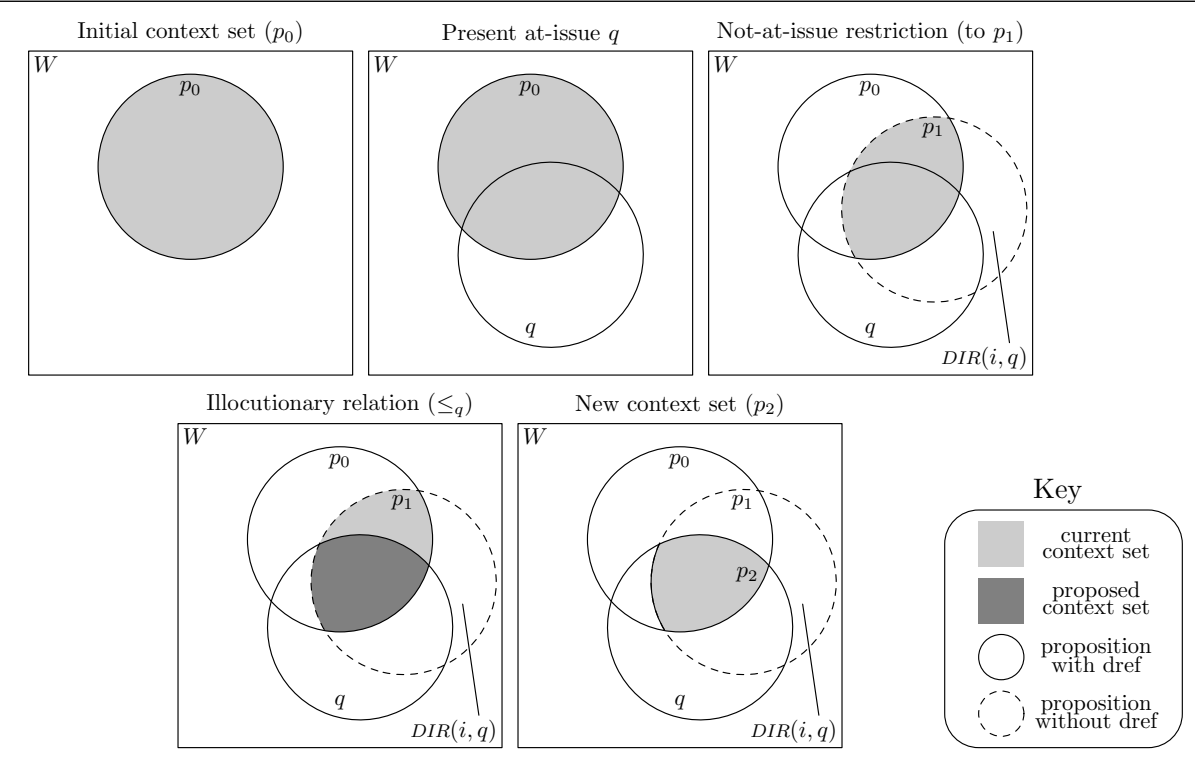

Figure 1 Updates for (11): Cheyenne direct evidential

In the second diagram in Figure 1, a discourse referent is introduced for the at-issue proposition $q$, but this information is not yet added to the common ground. This represents the presentation of the at-issue proposition as the 'main point' of the sentence, setting the topic under discussion, or addressing a question under discussion (see, e.g., Roberts 1996, Simons et al. 2010).

6 I assume a discourse referent for the context set. This can, for example, serve as the default domain for modals (see, e.g., Roberts 1989, Stone 1999). 
Varieties of update

The third diagram is the not-at-issue restriction, directly updating the common ground, indicated by reducing the context set to $p_{1}$. The context set now includes only worlds where the evidential proposition $\operatorname{DIR}(i, q)$ is true. There are still worlds where the at-issue proposition $q$ is true and worlds where $q$ is false. No discourse referent is introduced for the evidential proposition, indicated by a dashed line. However, this information is still present, recoverable, and indirectly challengeable. It is just not as easily accessible as the at-issue information, not pre-packaged for anaphoric reference.

A not-at-issue restriction can be seen as a semantic correlate of the pragmatic secondary effect of assertion from Stalnaker 1978, which is the automatic addition of certain new information to the common ground (e.g., who is speaking, what language she is using). ${ }^{7}$ This contrasts with presuppositions, which I take to be constraints on the input context. Like the secondary effect of assertion, not-at-issue restrictions are not negotiable, not directly challengeable, and are added even if the at-issue proposition is denied. Unlike the secondary effect of assertion, not-at-issue restrictions are semantic, part of the conventional meaning contributed by an item in the sentence, such as an evidential marker.

The fourth diagram in Figure 1 represents the illocutionary relation, contributed by the illocutionary mood of the sentence. For declarative sentences, this is the proposal to add a proposition to the common ground (Groenendijk \& Roelofsen 2009, Farkas \& Bruce 2010, Murray 2010), modeled here as a type of context structuring update. ${ }^{8}$ For (11), the proposal is to add the at-issue proposition $q$ to the common ground, to further reduce the context set to only $q$-worlds (labeled as $\leq_{q}$ to indicate $q$-worlds are the proposed worlds to update to). This proposal is illustrated with the proposed $q$-worlds shaded darker than the rest.

The proposal to update the common ground with the at-issue proposition is the effect that characterizes (at-issue) assertion (as in Ginzburg 1996, Groenendijk \& Roelofsen 2009, Farkas \& Bruce 2010, among others). This is related to the analysis of assertion in Stalnaker 1975, 1978, who treats the essential effect of an assertion as intersecting the proposition expressed

7 Modeled as intersection, not-at-issue restriction also resembles the formal definition of the primary effect of assertion in Stalnaker 1975 (though this rule was intended to be supplemented with pragmatic rules for blocking this effect). Thus, I have also used the term not-at-issue assertion for this treatment of not-at-issue content (Murray 2009, 2010).

8 A proposal to update the common ground could be treated as a distinct type of update. However, I treat it as a kind of structuring update, since other moods, e.g., imperative and interrogative, can also be seen as contributing structuring updates. 
with the context set, provided no one objects; the rejection of an assertion is treated as blocking this effect, leaving the input common ground unchanged. In contrast, I treat the proposal nature of assertion as a semantic contribution of declarative mood: its illocutionary relation structures the context, encoding the proposal to update further with the asserted proposition.

The fifth diagram in Figure 1 represents the introduction of a discourse referent for the new, further reduced context set. I assume that all declarative clauses introduce a new context set, representing the progress of information exchange (adapting Stalnaker 1975, 1978 as well as Stone 1999, who uses modal referents in analyzing modals and modal subordination; see also Bittner 2009, 2011). This update incorporates the tacit acceptance of the proposal to reduce the context set to $q$-worlds. Other updates contributed by the sentence, including the proposal and the introduction of the discourse referent for $q$, provide structure for subsequent denials, objections, and challenges to pick up on. No such structure is present for the not-at-issue content, which is not directly challengeable.

This new, reduced context set encodes the truth conditions for the sentence - the change in content from the initial context set - and signals that declarative sentences have truth values (see Bittner 2011). Thus, the truth conditions for (11) are that the speaker has direct evidence that Sandy won and that Sandy won. Crucially, this analysis captures the fact that these added propositions have different statuses and affect the context in different ways, and it can do so compositionally. In addition, the evidential contribution will remain even if the at-issue proposition is denied.

This approach allows for a unified semantic analysis of different morphosyntactic moods: they introduce different illocutionary relations, different kinds of structuring updates. For example, English and Cheyenne polar interrogative mood, in (12) and (13), can be analyzed as contributing a structuring update that partitions the context set, illustrated in Figure 2, implementing Groenendijk \& Stokhof 1984 and Groenendijk 1999.

(12) Did Sandy win?

(13) É-hótäheva-he Sandy? = (5) 3-win-Y/N Sandy

'Did Sandy win?' 


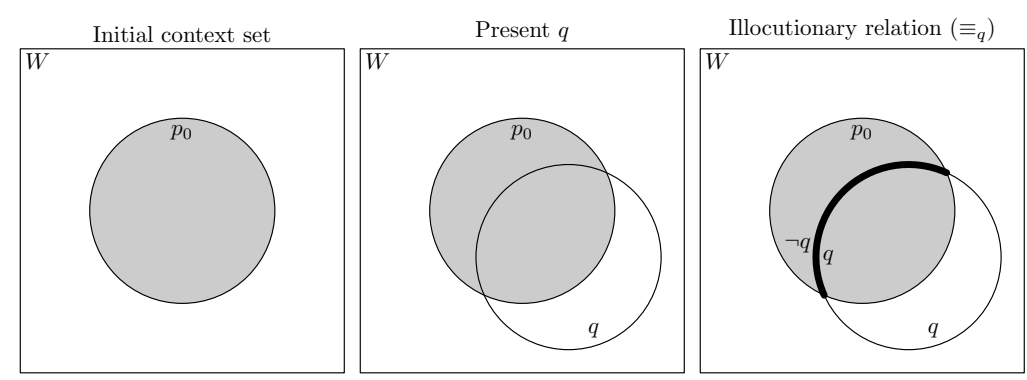

Figure 2 Updates for (12) and (13): polar interrogative mood

The first diagram in Figure 2 represents the initial context set. In the second diagram, a discourse referent is introduced for the at-issue proposition $q$. The third diagram in Figure 2 represents the structuring update that partitions the context set into $q$-worlds and $\neg q$-worlds. It introduces discourse referents for $q$ and $\neg q$, setting up the possible answers (incorporating Hamblin 1973). There is no not-at-issue content in (12) or (13) and so no not-at-issue restriction, no information is added to the context set, and no new discourse referent for a new context set is introduced.

Under the hypothesis that the semantic contribution of illocutionary mood is an illocutionary relation, all moods should introduce structuring updates. Declarative mood contributes the proposal to add a proposition to the common ground and polar interrogative mood contributes a partition of the context (or more generally a cover) - these are two kinds of structuring updates. Imperative mood can be analyzed as contributing a preference relation on the context, following Starr 2010, a third kind of structuring update. These three kinds of structuring updates account for the three major sentence types cross-linguistically. A hypothesis for future research is that they, and perhaps combinations of them, can provide an analysis of all grammatical moods. For example, Cheyenne hortative mood ( $\approx$ Let him sing!), similar to imperative mood, could also be analyzed as contributing a type of preference relation, but about a third person rather than the addressee.

Analyzing mood as semantically contributing an illocutionary relation also allows for a unified analysis of phenomena that affect the "force" of an utterance of a sentence: they affect the propositional argument of the structuring update. For example, various phenomena lessen the commitment to the at-issue proposition, including evidentials (e.g., Faller 2002, 2006, Matthewson, Rullmann \& Davis 2007, Murray 2010). Consider Cheyenne (14), 
which, like reportatives in some other languages, makes no commitment to the at-issue proposition.

(14) É-hó'täheva-séstse Sandy.

'Sandy won, I hear.'

Parallel to Cheyenne (11), I analyze (14) as making three semantic contributions. It has the same at-issue proposition as (11), that Sandy won, but a different not-at-issue restriction and illocutionary relation. The updates for (14) are illustrated below in Figure 3, where $\operatorname{RPT}(i, q)$ is the proposition that the speaker $(i)$ has reportative evidence (RPT) for the at-issue proposition $(q)$.

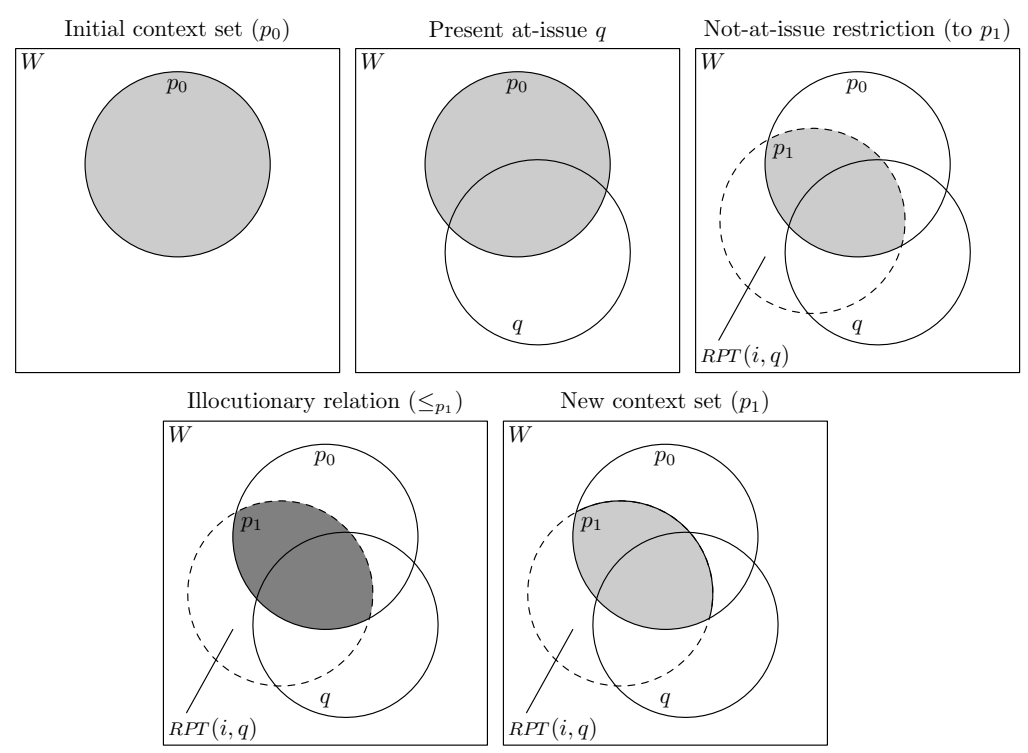

Figure 3 Updates for (14): Cheyenne reportative evidential

The diagrams in Figure 3 are parallel to those for (11) in Figure 1, the differences resulting from the not-at-issue content and the proposal. The not-at-issue restriction directly updates the context set to $p_{1}$, the worlds where $\operatorname{RPT}(i, q)$ is true, represented in the third diagram. As with (11), no discourse referent is introduced for the evidential proposition.

Because the reportative does not commit the speaker at all to the truth or the possibility of the at-issue proposition, in contrast to (11), I analyze (14) as contributing a proposal to keep all current context set worlds $\left(\leq_{p_{1}}\right)$ - in other 
Varieties of update

words, to not update further. ${ }^{9}$ This is represented in the fourth diagram: the proposal is to keep all $p_{1}$-worlds, including both $q$-worlds and $\neg q$-worlds. In this respect, the Cheyenne reportative is a hedge, an element that explicitly affects the force of an utterance. In declaratives, a hedge affects the level of commitment to the at-issue proposition, as in English (8). For Cheyenne (14), the level of commitment to $q$ is none. This is captured compositionally because the declarative mood still contributes the same type of illocutionary relation, a proposal to add a proposition $r$ to the common ground $\left(\leq_{r}\right)$. For the reportative, the propositional argument of this relation is the current context set $p_{1}\left(\leq_{p_{1}}\right)$, compared to $q$ for the direct evidential $\left(\leq_{q}\right)$.

The fifth diagram in Figure 3 represents the introduction of a discourse referent for the new context set, an update which is part of all clauses with declarative mood. Here, the context set is still $p_{1}$. This context set encodes the truth conditions for the Cheyenne reportative sentence (14): that the speaker has reportative evidence that Sandy won. The truth conditions do not include any conditions on the truth of the at-issue proposition. In languages where the reportative behaves differently, the propositional argument of the illocutionary relation could be different. I return to this issue when discussing English parentheticals, below in Section 2.2.

The proposed analysis of the Cheyenne reportative is similar in certain respects to the analysis of Cuzco Quechua reportatives in Faller 2002, and in many ways I am trying to implement some of the intuitions introduced there for similar data. However, there are some crucial formal and empirical differences. For Faller 2002, evidentials are speech act modifiers, functions from speech acts to speech acts. The evidential proposition is a sincerity condition of the modified speech act, as Faller 2002 does not want evidentials to be truth conditional. In contrast, on the proposed analysis evidentials contribute to the truth conditions. This allows for an account of various Cheyenne data, e.g., contradictions, not otherwise available (Murray 2010). On the proposed analysis, evidentials are not speech act modifiers. They contribute a not-at-issue restriction, which just updates the common ground in the usual fashion, but with a different status. They do not change the kind of structuring relation contributed by the mood of the sentence, only the propositional argument of it. This accounts for evidentials in declaratives, as discussed here, as well as in interrogatives (see Murray 2010). Lastly,

9 An alternative approach is to analyze Cheyenne reportative sentences as not having a proposal component (see Murray 2010). Even so, they would still be considered a declarative sentence, because of the introduction of a new context set (fifth diagram in Figure 3). 
here the direct challengeability facts (see (6) and (7) above) are explained by propositional anaphora, by which propositions are represented by discourse referents, instead of stipulating that sincerity conditions are not challengeable. This better accounts for indirect challenges and predicts that embeddability facts should parallel the direct challengeability facts.

This treatment of the Cheyenne reportative is similar in other respects to the Ciardelli, Groenendijk \& Roelofsen 2009 treatment of English might: it draws attention to the prejacent proposition but does not propose to add it to the common ground. However, the two analyses differ in several important ways. For Ciardelli, Groenendijk \& Roelofsen 2009, attention is represented by a non-maximal proposition, a subset of the context set. On the analysis proposed here, a discourse referent for the entire proposition is introduced, not just for a subset of the context set. For Ciardelli, Groenendijk \& Roelofsen 2009, attentiveness requires a non-maximal proposition and so not all sentences are attentive, while here all sentences introduce discourse referents for the at-issue proposition. Perhaps most significant is that on the proposed analysis the reportative also contributes a not-at-issue restriction: the evidential proposition is directly added to the common ground.

Because Cheyenne sentences with the reportative evidential make no commitment to the at-issue proposition, the at-issue proposition can be explicitly denied, as in (15), repeated from (10) above. ${ }^{10}$

i. É-hó'táheva-séstse
3-win-RPT.3SG

Each conjunct of (15) contains a different at-issue proposition - that Sandy won for (i) and that Sandy didn't win for (ii) - as well as a different evidential - the reportative for (i) and for (ii) the direct. An analysis of this deniability follows from the above analyses of the direct and reportative evidentials, treating conjunction as sequential update (e.g., Groenendijk \& Stokhof 1991, Veltman 1996, a.o.). Because there are two matrix clauses in (15), both declarative, there are two structuring updates and two updates that introduce a new context set. Declarative mood, compatible with any type of evidential, contributes both of these updates. The difference comes in

10 A variant of (15) with a reportative in the second conjunct (15ii) instead of the direct is odd, arguably because sequential reportatives are typically taken to be from the same source. 
Varieties of update

the content of the illocutionary relation: what proposition is proposed to be added to the common ground.

The updates contributed by (15i) and (15ii) are compatible, resulting in an output context set that encodes the truth conditions: that the speaker has reportative evidence that Sandy won, that the speaker has direct evidence that Sandy did not win, and that Sandy did not win.

So far, this section has shown that we can analyze evidentials and mood marking compositionally with three kinds of update: direct updates, structuring updates, and updates that introduce discourse referents. All mood marking contributes a structuring update, which uses a proposition to structure the context. This can be extended to dependent and embedded moods by taking them to operate on a set of worlds other than the context set.

Different kinds of evidentials in Cheyenne, e.g., direct and reportative, are given a unified analysis. They have the same at-issue proposition, the same 'proposition expressed', which is neither an evidential proposition nor a modal proposition. They both contribute a not-at-issue restriction, but with different evidential content. Lastly, the difference in commitment to the at-issue proposition is analyzed as a difference in the propositional argument of the illocutionary relation. The reportative affects what this argument is, altering the level of commitment compositionally. That will be the analysis for all hedges.

Evidentials within a language and crosslinguistically can differ in many respects on this analysis: whether the at-issue proposition is modal, what the content of the not-at-issue restriction is, and what the level of commitment to the at-issue proposition is. This allows for a wide range of evidential systems.

Before moving on to other phenomena that can be analyzed by distinguishing these varieties of update, it is worth mentioning again that I have been assuming that the evidential proposition is not-at-issue and the proposition in the evidential's scope is at-issue. In Cheyenne, and many other languages with grammatical evidentials, I think this must be the case. Cheyenne evidentials are verbal suffixes, part of the inflectional system, and I argue grammatically not-at-issue (Murray 2010). However, it is conceivable that in some languages either the evidential proposition or the proposition in the evidential's scope could be at-issue. So, a distinction should be made between phenomena that must contribute not-at-issue content and phenomena that can contribute not-at-issue content. For example, evidential embedding 
verbs in English can have variable at-issue status. Consider English (16), adapted from Simons 2007, which shows that embedding verbs in English can have evidential uses. In the context of (16a), the main clause of (16b) is not-at-issue while the embedded clause is at-issue. This contrasts with (17): in the context of $(17 a)$, the main clause of $(17 b)(=(16 b))$ is at-issue.

(16) a. Who won the race last night?

b. I heard that Sandy won. at-issue: $q$, not-at-issue: heard $(i, q)$

(17) a. What did you hear?

b. I heard that Sandy won. at-issue: heard $(i, q)$, not-at-issue: $q$

English $(16 b) /(17 b)$ should be analyzed as contributing two propositional discourse referents, one for each clause, and the context will determine which is at-issue. In all other respects, English (16b) can be analyzed as parallel to Cheyenne (14): the evidential proposition is not-at-issue and there is no commitment to the at-issue proposition (that Sandy won). ${ }^{11}$ In (17b), the evidential proposition is at-issue and so it is the evidential proposition that is proposed to be added to the common ground. In both cases, the declarative mood contributes the same structuring relation, but because the at-issue proposition is different, the effect of the illocutionary relation is different. If there are grammatical evidentials that contribute content that can be either at-issue or not-at-issue, a parallel analysis could be given.

For Simons et al. 2010, examples like (16) and (17) support defining atissueness as relative to the Question Under Discussion (QUD). However, a definition of at-issueness should take into account both discourse structure and grammatical status. As discussed above for Cheyenne evidentials, certain elements cannot be made at-issue, even if they could, in principle, address the QUD. Consider English (18): (18a) is the same as (17a), and so should make the evidential proposition at-issue.
a. What did you hear?
b. \# Sandy won, I hear(d).
at-issue: $q$, not-at-issue: $h e a r d(i, q)$

However, the response in (18b) is infelicitous: the parenthetical cannot bear the at-issue information. Like Cheyenne evidentials, English evidential parentheticals like I hear in (18b) must contribute not-at-issue content. Unlike

11 This is supported by the deniability of the at-issue proposition q: I heard that Sandy won, but she didn't. If there were some commitment to $q$, (16b) could be analyzed parallel to (20). 
Varieties of update

English evidential embedding verbs, English parentheticals and Cheyenne evidentials do not have variable at-issue status. Our semantics for these constructions must reflect this. In the proposed analysis of Cheyenne evidentials, this is captured because no discourse referent is introduced for the evidential proposition, so it cannot be made at-issue. A similar solution is proposed for English parentheticals in the next section.

\subsection{Parentheticals and appositives}

Distinguishing the three varieties of update discussed in the previous section also allows for an analysis of parentheticals and appositives, phenomena related to evidentials and mood, and similarly difficult to analyze without these distinctions (see, e.g., Asher 2000, Jayez \& Rossari 2004, Potts 2005, Nouwen 2007, AnderBois, Brasoveanu \& Henderson 2010, Koev 2012). Before considering examples of English sentences with parentheticals and appositives, first consider (19), a plain English sentence with no new not-at-issue content. $^{12}$

(19) Floyd won the race.

In (19), the at-issue proposition is that Floyd won the race and the illocutionary mood is declarative. This sentence makes two semantic contributions, illustrated in Figure 4 below: a presentation of the at-issue proposition and a declarative illocutionary relation. No not-at-issue restriction is contributed.

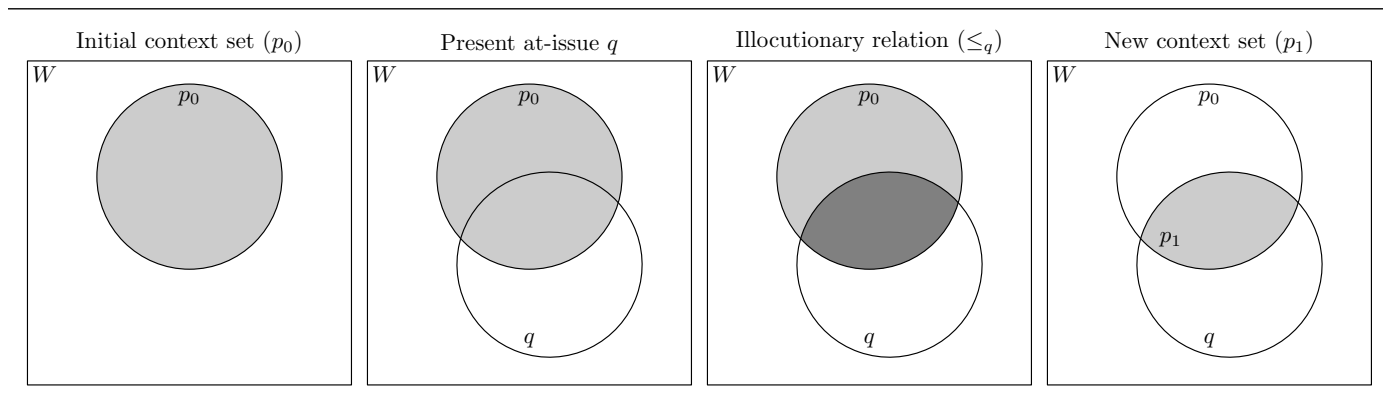

Figure 4 Updates for (19): simple English sentence (no not-at-issue content)

12 Perhaps the presuppositions triggered in (19) are also not-at-issue, but I assume they are analyzed as constraints on the input context, unlike the not-at-issue restrictions discussed here, which typically add new information to the common ground. 
In the second diagram in Figure 4, a discourse referent is introduced for the at-issue proposition $q$. No information is added to the context set yet. The third diagram represents the illocutionary relation, the structuring update that proposes to add $q$ to the common ground. The fourth diagram in Figure 4 represents the new, reduced context set $p_{1}$, with the information that $q$ added. For (19), the truth conditions are that Floyd won the race. On this view, Cheyenne (11) is stronger than English (19) in that it contributes more information, namely, the evidential not-at-issue restriction.

An evidential parenthetical, as in the English slifting construction in (20), adds two things to the sentence: it adds a not-at-issue restriction that the speaker heard that $q$ (heard $(i, q)$ ) and it lessens the level of commitment to the truth of $q$. The parenthetical affects the assertive force, so that English (20) no longer fully asserts that Floyd won the race (see also Jayez \& Rossari 2004). So, in analyzing (20), we do not want to reduce the context set to only worlds where Floyd won, as we did for (19) in Figure 4.

\section{(20) Floyd won the race, I hear.}

Instead, the evidential parenthetical in (20) hedges the assertion. I treat such parentheticals along the lines of the Cheyenne reportative above: it can modify the propositional argument of the illocutionary relation. The illocutionary relation for the declarative mood is the same as always: the proposal to add a proposition to the common ground. However, what this proposition is can change, depending on various sentential modifiers, such as evidential parentheticals, or adverbs, maybe modals.

Let us assume English (20) requires that the at-issue proposition is at least possible. Then, to analyze (20), we want to propose eliminating some, but not all, $\neg q$-worlds. The exact force can vary, so I use $\diamond q$ as a rough approximation of a proposition that includes $q$-worlds as well as $\neg q$-worlds where $q$ is accessible. What exact proposition is proposed to be added to the common ground, that $q$ is possible, that $q$ is likely, that $q$ is probable, depends on the level of commitment of the parenthetical: I think, I gather, I guess, I hear, they say, and so on (see also Kratzer 1991 on graded modality). The illocutionary relation of a sentence constrains the force of its interpretation, so changing its propositional argument allows for different constraints on its force, and thus different kinds of hedges, with different levels of commitments, including no commitment. The updates for (20) are given below in Figure 5. 
Varieties of update

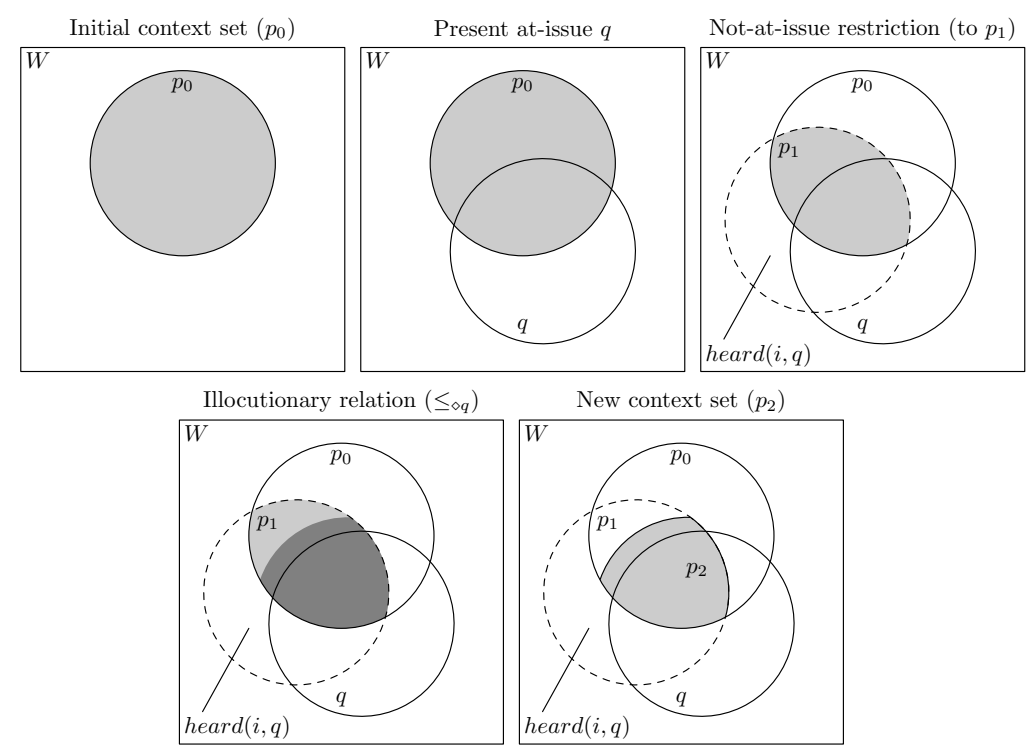

Figure 5 Updates for (20): English evidential parentheticals

Figure 5 for (20) is similar to Figure 4 for (19), with two changes. First, a not-at-issue restriction directly updates the context set to the worlds where the speaker heard that $q$ (heard $(i, q)$ ). Thus, on the proposed analysis, as for Asher 2000, this contribution of the parenthetical is truth conditional. Second, the propositional argument of the illocutionary relation is different:

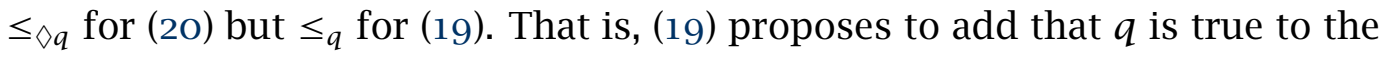
common ground, while (20) proposes to add that $q$ is possible. In the final update, a discourse referent is introduced for the new, reduced context set $p_{2}$, worlds where the speaker heard that $q$ and that $q$ is possible.

English (20) is similar to Cheyenne sentences with the reportative evidential, such as (14), but it contributes more of a commitment to the at-issue proposition. Closer English correlates of Cheyenne (14) include sentences with not-at-issue evidential embedding verbs, like (16b). In addition, some English sentences with parentheticals arguably do not commit the speaker at all to the at-issue proposition. For example, (21) seems to be deniable in the way that Cheyenne (14) is, as in (22).

(21) Floyd won the race, they say.

(22) Floyd won the race, they say, but I was there and he didn't. 
If so, the analysis of (21) could directly parallel the analysis of Cheyenne (14), given in Figure 3, potentially with a slightly different not-at-issue restriction.

An important feature of this account of parentheticals is how modality is(n't) involved. Neither the at-issue proposition, that Floyd won the race, nor the evidential proposition, that the speaker heard that Floyd won the race, is modal. This is an advantage because examples like (20) and (21) do not contain any overt modals. Modality comes into play only in the illocutionary relation, in determining what proposition is added to the common ground. I would give a parallel analysis to the Cheyenne conjectural evidential, which is not modal, in that neither the at-issue proposition nor the evidential proposition contains a modal. For languages where evidentials are modals, the content of either proposition could be different.

Like evidentials and evidential parentheticals, sentences with appositive relative clauses, as in (23), contribute two propositions with different statuses (del Gobbo 2003, Potts 2005, Nouwen 2007, AnderBois, Brasoveanu \& Henderson 2010, Koev 2012, a.o.). Unlike evidentials and parentheticals, appositives like the one in (23) do not seem to affect the level of commitment to the at-issue proposition. Nonetheless, the semantic contributions of appositives fit into the proposed distinctions between the three varieties of update. Consider English (23), which contains an appositive relative clause, and (24), without the appositive.

(23) Tivi, who is a cat, likes to chase her tail. =(3)

(24) Tivi likes to chase her tail.

The at-issue proposition for both (23) and (24) is that Tivi likes to chase her tail. The appositive in (23) contributes a not-at-issue restriction that Tivi is a cat. This appositive does not affect force, an effect seen above with hedges. It does, however, help with the interpretation of the rest of the sentence. It helps to satisfy the presupposition introduced by her tail. It also preempts the inference that Tivi is a dog, since chasing one's tail is an activity typically associated with dogs, not with cats, even speedy, playful ones. These can be seen as results of the not-at-issue restriction. Parallel to the not-at-issue content contributed by evidentials and evidential parentheticals, no propositional discourse referent is introduced for the proposition that Tivi is a cat, and this proposition is not directly challengeable (see (7) above and Amaral, Roberts \& Smith 2007, Koev 2012, a.o.). 
Varieties of update

The analysis of (24) would be directly parallel to (19), with a different at-issue proposition. For (23), the analysis is that for (24) plus a not-at-issue restriction to worlds where Tivi is a cat, as illustrated in Figure 6 below.

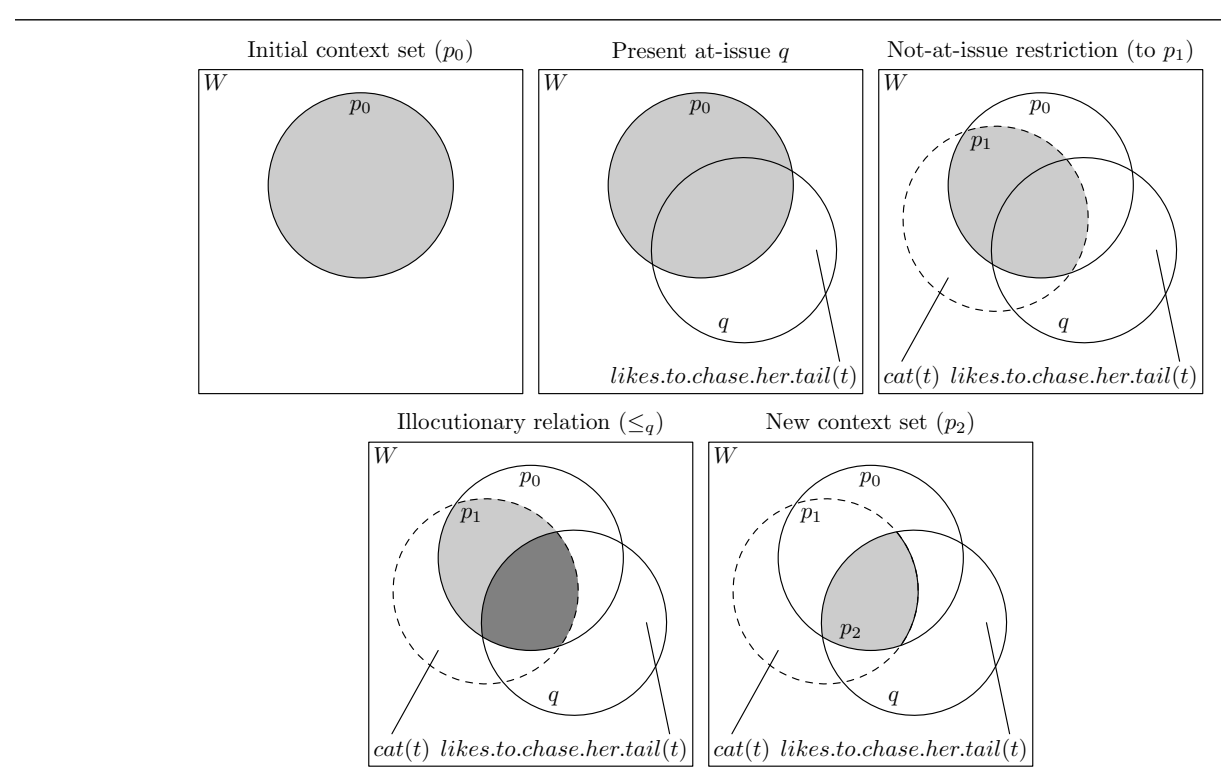

Figure 6 Updates for (23): English appositive

Unlike evidentials, the anchor of the appositive is a nominal, not the at-issue proposition. Thus, the introduction of the discourse referent for the at-issue proposition and the not-at-issue restriction could occur in either order.

Of existing semantic analyses of appositives (Potts 2005, Nouwen 2007, Schlenker 2010, AnderBois, Brasoveanu \& Henderson 2010, Koev 2012, a.o.), the proposed analysis most closely resembles AnderBois, Brasoveanu \& Henderson 2010, with a few important differences. For AnderBois, Brasoveanu \& Henderson 2010, no propositional discourse referent is introduced for the entire at-issue proposition. Instead, one is introduced for the subset of the context set where the at-issue proposition is true $\left(p \subseteq p^{c s}\right)$, the darker shaded worlds in the above diagrams, which represent the proposal. As discussed above, a discourse referent for the entire at-issue proposition is needed to account for various phenomena, including challengeability, evidentials, and the deniability of the reportative's scope. For example, with evidentials the speaker does not just have evidence for the context set worlds where the at-issue proposition is true. Further, the proposed analysis of mood and hedges requires separate representations of the at-issue proposition and the proposal. See Section 4 for further discussion. 


\subsection{Summary}

In this section, I have given a unified analysis of a wide range of phenomena by distinguishing three varieties of update: direct updates of the common ground, structuring updates, and updates introducing discourse referents, with special attention to propositional discourse referents for at-issue content. Each of these three kinds of semantic contributions is new to the context: new information, new structure, new discourse referents.

All sentences potentially contribute these three kinds of update, with each introduced by different kinds of phenomena. Appositives, evidentials, and parentheticals contribute not-at-issue restrictions, modeled as direct updates to the common ground. Mood marking contributes an illocutionary relation, analyzed as a structuring update. Evidentials and parentheticals can also alter the argument of the illocutionary relation, affecting the force of an utterance of the sentence. A discourse referent is always introduced for the at-issue proposition, but not necessarily for not-at-issue propositions.

Table 1 summarizes the types of data discussed in this section. ${ }^{13}$

\begin{tabular}{|c|c|c|c|}
\hline & AI & NAI & IR \\
\hline i Sandy 3-win-DIR. =(11) & $q$ & $\operatorname{DIR}(i, q)$ & $\begin{array}{c}\text { propose } \\
\mathrm{CS}^{\prime}=\mathrm{CS} \cap q\end{array}$ \\
\hline ii Sandy 3-win-RPT. =(14) & $q$ & $\operatorname{RPT}(i, q)$ & $\begin{array}{c}\text { propose } \\
\mathrm{CS}^{\prime}=\mathrm{CS} \cap \mathrm{CS}\end{array}$ \\
\hline iii Sandy 3-win-Y/N? =(13) & $q$ & & $\begin{array}{l}\text { partition } \\
\text { cs with } q\end{array}$ \\
\hline iv Did Sandy win? =(12) & $q$ & & $\begin{array}{l}\text { partition } \\
\text { CS with } q\end{array}$ \\
\hline v Sandy won. $\approx(19)$ & $q$ & & $\begin{array}{c}\text { propose } \\
\mathrm{CS}^{\prime}=\mathrm{CS} \cap q\end{array}$ \\
\hline vi Sandy won, I hear. $\approx(20)$ & $q$ & heard $(i, q)$ & $\begin{array}{c}\text { propose } \\
\mathrm{CS}^{\prime}=\mathrm{CS} \cap \diamond q\end{array}$ \\
\hline vii Sandy, who is a redhead, won. $\approx(23)$ & $q$ & $\operatorname{redhead}(s)$ & $\begin{array}{c}\text { propose } \\
\mathrm{CS}^{\prime}=\mathrm{CS} \cap q\end{array}$ \\
\hline
\end{tabular}

Table 1 Summary: Semantic contributions of various phenomena

13 The first three are Cheyenne examples, listed by their glosses. The other four are English examples, modified as needed to have the same at-issue proposition, that Sandy won $(q)$, for comparison. Abbreviations are: AI for at-issue proposition, which is represented by a discourse referent; NAI for not-at-issue proposition, which is directly added to the common ground; IR for illocutionary relation; cs for context set; and Cs' $^{\prime}$ for the updated context set. 
Varieties of update

Each of the examples in Table 1 contributes at least an at-issue proposition and an illocutionary relation. It is conceivable, though, that certain phenomena may not make these contributions. Sentential examples always have mood marking, but perhaps non-sentential expressions like ouch! contribute only not-at-issue content. Embedded constructions like (16b) arguably contribute multiple propositional discourse referents, one for each clause, but are otherwise parallel to (vi) above. Thus, while at-issue information must be represented by a propositional discourse referent, not-at-issue information may or may not be, depending on the construction.

The discussion in this section has been relatively theory neutral, making certain semantic assumptions, but none that are specific to any particular implementation. The core proposal of distinguishing these three kinds of semantic contributions is not implementation specific, and need not be tied to any particular formalization. That said, I now turn to describing a formal system that can integrate these distinctions into a single semantic representation. In part, this is to show that such a thing can be done. It is also vital to making specific empirical predictions about data from various languages, to test the empirical adequacy of making such distinctions.

\section{Varieties of update: Formal implementation}

In order to model the various kinds of update discussed in the previous section, a system that can represent several things is needed: changes in the context set, and thus the truth-conditional information; anaphora, including propositional anaphora, to represent at-issue propositions, and nominal anaphora, for the anchor of appositives; a way to distinguish at-issue and notat-issue content; and a rich enough representation of context to implement the idea that the illocutionary relation of a sentence structures this context.

For these purposes, I use Update with Modal Centering (Bittner 2011), which has discourse referents for individuals, worlds, and propositions. This is a fragment of a more general system, Update with Centering (Bittner 2009, 2011), which also has referents for events, states, and times.

Update with Centering builds on Predicate Logic with Anaphora (Dekker 1994), an update semantics (e.g., Veltman 1996) where an information state is a set of sequences of individuals (see also van Eijck \& Nouwen 2002, building on Vermeulen 1993, van Eijck 2001, and van den Berg 1996). Update with Centering extends this in two ways: (i) each information state is a set of pairs of sequences and (ii) sequences can contain objects of various types. These 
additions were made to account for grammatical centering and centering parallels across domains (see Bittner 2009, 2011, building on Grosz, Joshi \& Weinstein 1995, Hardt 1996, Stone 1997, Stone \& Hardt 1999).

So, in Update with Modal Centering (henceforth $\mathrm{UC}_{\omega}$ ), an information state is (the characteristic function of) a set of pairs of sequences. Each pair is composed of a top $(T)$ sequence and a bottom $(\perp)$ sequence: $\langle T, \perp\rangle$. Each sequence is composed of objects of the following types: individuals, worlds, and propositions. In the $\mathrm{UC}_{\omega}$ information states in Table 2 below, depicted as matrices, $w_{0}, w_{1}$, and $w_{2}$ are worlds and $p_{0}, p_{1}$, and $q$ are propositions.

$$
\begin{aligned}
& \frac{c}{\left\{\left\langle\left\langle w_{0}, p_{0}\right\rangle,\langle\rangle\right\rangle,\right.} \quad \frac{c^{\prime}}{\left\{\left\langle\left\langle w_{0}, p_{0}\right\rangle,\left\langle q, w_{1}\right\rangle\right\rangle,\right.} \quad \frac{c^{\prime \prime}}{\{} \\
& \left\langle\left\langle w_{0}, p_{0}\right\rangle,\left\langle q, w_{2}\right\rangle\right\rangle \text {, } \\
& \left\langle\left\langle w_{1}, p_{0}\right\rangle,\langle\rangle\right\rangle \quad\left\langle\left\langle w_{1}, p_{0}\right\rangle,\left\langle q, w_{1}\right\rangle\right\rangle, \quad\left\langle\left\langle p_{1}, w_{1}, p_{0}\right\rangle,\left\langle q, w_{1}\right\rangle\right\rangle, \\
& \} \quad\left\langle\left\langle w_{1}, p_{0}\right\rangle,\left\langle q, w_{2}\right\rangle\right\rangle\right\} \quad\left\langle\left\langle p_{1}, w_{1}, p_{0}\right\rangle,\left\langle q, w_{2}\right\rangle\right\rangle\right\}
\end{aligned}
$$

Table 2 Sample $\mathrm{UC}_{\omega}$ information states

I use these pairs to distinguish at-issue and not-at-issue information: the top sequences represent the context set, to which not-at-issue information is directly added, and the bottom sequences represent at-issue information. ${ }^{14}$

For example, consider the information states in Table 2. In state $c$, the context set is $p_{0}$, which is composed of worlds $w_{0}$ and $w_{1}$. The worlds in $p_{0}$ are represented distributively across the information state, with one pair (row) per world (adapting the plural information states of van den Berg 1996). In $c^{\prime}$, at-issue information has been added to the bottom sequence: the worlds where the at-issue proposition is true, $w_{1}$ and $w_{2}$, and the set of those worlds, $q$, the at-issue proposition..$^{15}$ Information can be added to the context set by eliminating all pairs with a certain top world: to add the information $q$ to the context set, eliminate all pairs where the top world is not a $q$-world. This is illustrated in $c^{\prime \prime}$, where all rows with $w_{0}$ (a $\neg q$-world) in the top sequence have been eliminated. In addition, $c^{\prime \prime}$ contains a new proposition $p_{1}$ for the new context set $\left\{w_{1}\right\}$. In this example, $q$ was the

14 Bittner 2009, 2011 use the top sequence to represent the context set, to track truth conditions (building on Brasoveanu 2007, a.o.), but do not discuss the at-issue/not-at-issue distinction. 15 Maximization is built into updating. When a referent is introduced, for each sequence in the input, there are as many output sequences as objects that satisfy the conditions of the update, ensuring no accidental dependencies between objects are introduced. 
Varieties of update

at-issue proposition; below, at-issue propositions are first proposed to be added to the context set. Not-at-issue information is analyzed as directly updating the context set: it eliminates top worlds without a proposal and without necessarily being represented by a discourse referent.

This update semantics is formalized in a many-sorted type logic, adapting Muskens 1995, 1996. Information states are type (st), the characteristic function of a set of pairs of sequences, so updates are type (st)st. (A pair, itself a sequence of length 2, is type $s$.) DRT-style abbreviations for lambda terms are used, as in (25), following Muskens 1996, Stone 1999, among others (adapting, e.g., Kamp 1981, Kamp \& Reyle 1993). The update specified in (25i) is a test on each pair: the output state is the set of pairs from the input state that satisfy the conditions $C$. Update (25ii) appends an object to the top sequence $\left({ }^{\top} \oplus\right)$, while (25iii) appends an object to the bottom sequence $\left(^{\perp} \oplus\right.$ ). The sequencing operator ; composes updates (25iv).

$$
\begin{aligned}
& \text { i. }[C] \\
& \text { for } \lambda I_{s t} \lambda j_{s} . I j \wedge C j \\
& \text { ii. }{ }^{\top}\left[u_{1} \mid C\right] \text { for } \lambda I_{s t} \lambda j_{s} . \exists u_{1} \exists i_{s}\left(j=\left(u_{1}^{\top} \oplus i\right) \wedge I i \wedge C i\right) \\
& \text { iii. }\left[u_{1} \mid C\right] \text { for } \lambda I_{s t} \lambda j_{s} . \exists u_{1} \exists i_{s}\left(j=\left(u_{1}{ }^{\perp} \oplus i\right) \wedge I i \wedge C i\right) \\
& \text { iv. }\left(J_{(s t) s t} ; K_{(s t) s t}\right) \text { for } \lambda I_{s t} \lambda j_{s} .(K(J I)) j
\end{aligned}
$$

Complete definitions and abbreviations for $\mathrm{UC}_{\omega}$ are given in Appendix A.

Information states in $\mathrm{UC}_{\omega}$ represent salience ranked discourse referents across domains. Consider the states in Table 3 , with $a, b$ for individuals (type $\delta$ ), $w_{0}, w_{1}$ for worlds (type $\omega$ ), and $p_{0}, q_{0}, q_{1}$ for propositions (type $\Omega:=\omega t$ ). Individuals can be introduced to either the top or bottom sequence; I assume here that the at-issue/not-at-issue distinction is for propositional content.

$$
\begin{aligned}
& \frac{c}{\left\{\left\langle\left\langle a, w_{0}, p_{0}\right\rangle\left\langle q_{0}, w_{0}\right\rangle\right\rangle,\right.} \quad \frac{c^{\prime}}{\left\{\left\langle\left\langle b, a, w_{0}, p_{0}\right\rangle\left\langle a, q_{1}, w_{1}, q_{0}, w_{0}\right\rangle\right\rangle,\right.} \\
& \left.\left.\left\langle\left\langle a, w_{1}, p_{0}\right\rangle\left\langle q_{0}, w_{0}\right\rangle\right\rangle\right\} \quad\left\langle\left\langle b, a, w_{1}, p_{0}\right\rangle\left\langle a, q_{1}, w_{1}, q_{0}, w_{0}\right\rangle\right\rangle\right\}
\end{aligned}
$$

Table 3 Sample $\mathrm{UC}_{\omega}$ information states

We can refer to the most prominent object of a type in a sequence: $T \delta$ for the most prominent (leftmost) individual $(\delta)$ on the top sequence $(T), T \omega$ for the most prominent world on the top sequence, $\perp \Omega$ for the most prominent proposition on the bottom sequence $(\perp)$, and so on. For state $c$ in Table 3 , $T \omega$ for the first pair is $w_{0}$ while $T \omega$ for the second pair is $w_{1}$. For both 
pairs in $c$, $\top \delta$ is $a$ and $\perp \Omega$ is $q_{0}$, while for both pairs in $c^{\prime} T \delta$ is $b$ and $\perp \Omega$ is $q_{1}$. We can also refer to less prominent objects by using subscripts: $\perp \Omega_{2}$ is the second most prominent proposition in the bottom sequence. For both pairs in $c^{\prime}, \perp \Omega_{2}$ is $q_{0}$. Because these are plural states, anaphora can be either local, within a pair (row), or global, across pairs (column). Global anaphors are written with the addition of $\|$, e.g., $T \omega \|$, intended to be mnemonic for a column. For example, for $c$ in Table $3, T \omega \|=\left\{w_{0}, w_{1}\right\}$ and $\perp \omega \|=\left\{w_{0}\right\}$.

$\mathrm{UC}_{\omega}$ can represent changes in the context set, tracking truth conditional information, and allows both nominal and propositional anaphora. To distinguish at-issue and not-at-issue information, I use the extension of sequence-based anaphora (Dekker 1994, van Eijck \& Nouwen 2002) to pairs of sequences: at-issue propositions are always represented by a discourse referent on the bottom sequence. Lastly, information states in $\mathrm{UC}_{\omega}$ are rich enough to represent structuring updates, as I discuss in detail below for mood. In the remainder of this section, all three varieties of update will be illustrated through a formal analysis of the phenomena discussed in Section 2: grammatical evidentials in Cheyenne, mood marking in both Cheyenne and English, evidential parentheticals in English, and English appositives. All of the examples from Section 2 will be repeated and an implementation of the analysis in Section 2 will be given for each.

\subsection{Evidentials and illocutionary mood}

In Section 2, I argued that Cheyenne (26) makes three semantic contributions: an update that introduces a propositional discourse referent for the at-issue proposition, a not-at-issue restriction that directly updates the context set, and a structuring update, the illocutionary relation, contributed by the mood of the sentence. These updates are illustrated in Figure 7, which is just Figure 1 with worlds added to illustrate the model used below.

(26) É-hó'tảhéva- $\varnothing$ Sandy. $=(11)$ 3-win-DIR Sandy

'Sandy won (I witnessed).' 


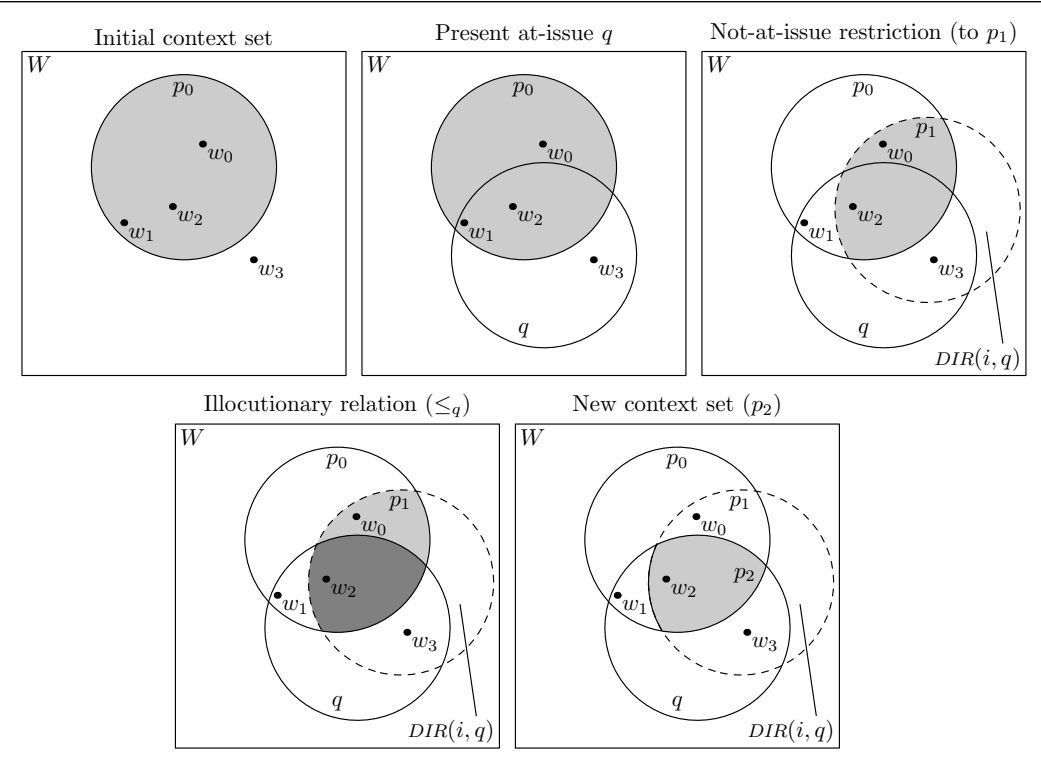

Figure 7 Updates for (26): Cheyenne direct evidential

As discussed above, I use the $\mathrm{UC}_{\omega}$ distinction between the top and bottom sequence to distinguish at-issue and not-at-issue content. I use the bottom sequence to track the at-issue propositions, propositions we are discussing, but are not (yet) committed to, and the top sequence to track the context set. Not-at-issue information directly eliminates worlds in the top sequence. At-issue information does not. Instead, at-issue information is added to the bottom sequence and a proposal is made about what to do with it. There could be a proposal to add it to the common ground, to add its possibility to the common ground, or to leave the common ground as is.

My translation of Cheyenne (26) into $\mathrm{UC}_{\omega}$ is (27). See Appendix A for complete definitions and abbreviations for $\mathrm{UC}_{\omega}$.

$$
\begin{aligned}
& \underbrace{{ }^{\mathrm{T}}[\mathrm{x} \mid \mathrm{x}=\text { sandy }] ;\left[\mathrm{w} \mid \text { won }_{\mathrm{w}}\langle T \delta\rangle\right] ;[\mathrm{p} \mid \mathrm{p}=\perp \omega \|]}_{\text {(present at-issue proposition } q \text { ) }} ; \\
& \underbrace{\left[\operatorname{DIR}_{T \omega}\langle\mathrm{i}, \perp \Omega\rangle\right]}_{\text {not-at-issue restriction) }} ; \underbrace{[\perp \omega \in T \omega \|] ;[\top \omega=\perp \omega]}_{\text {(illocutionary relation) }} ; \quad \underbrace{{ }^{\top}[\mathrm{p} \mid \mathrm{p}=\top \omega \|]}_{\text {(new context set) }}
\end{aligned}
$$

The first three updates present the at-issue proposition, here the proposition that Sandy won. These three updates are illustrated in Table 4 below, assuming the model in Figure 7 and the initial state $c_{0}$, which includes the initial context set $p_{0}$ and a pair for each world in it. The first update introduces 
an individual discourse referent for Sandy, adding the object $s$ to each top sequence, as in $c_{1}$. The second update introduces into each bottom sequence the worlds where she, the most prominent top individual $(T \delta)$, won, as in $c_{2}$. The third update introduces a propositional discourse referent for the at-issue proposition: the proposition composed of all of the (most prominent) bottom worlds $\left(q=\left\{w_{1}, w_{2}, w_{3}\right\}\right)$ is added to each bottom sequence, as in $c_{3} \cdot{ }^{16}$ All three of these updates just introduce discourse referents; no information is yet added to the context set: $T \omega \|$ is still $\left\{w_{0}, w_{1}, w_{2}\right\}$.

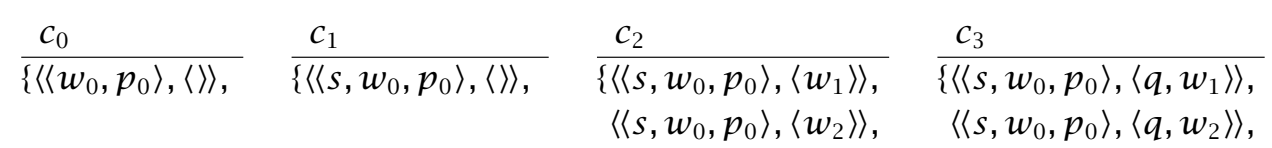

$$
\begin{aligned}
& \left\langle\left\langle s, w_{0}, p_{0}\right\rangle,\left\langle w_{3}\right\rangle\right\rangle, \quad\left\langle\left\langle s, w_{0}, p_{0}\right\rangle,\left\langle q, w_{3}\right\rangle\right\rangle, \\
& \left\langle\left\langle w_{1}, p_{0}\right\rangle,\langle\rangle\right\rangle, \quad\left\langle\left\langle s, w_{1}, p_{0}\right\rangle,\langle\rangle\right\rangle, \quad\left\langle\left\langle s, w_{1}, p_{0}\right\rangle,\left\langle w_{1}\right\rangle\right\rangle, \quad\left\langle\left\langle s, w_{1}, p_{0}\right\rangle,\left\langle q, w_{1}\right\rangle\right\rangle, \\
& \left\langle\left\langle s, w_{1}, p_{0}\right\rangle,\left\langle w_{2}\right\rangle\right\rangle, \quad\left\langle\left\langle s, w_{1}, p_{0}\right\rangle,\left\langle q, w_{2}\right\rangle\right\rangle, \\
& \left\langle\left\langle s, w_{1}, p_{0}\right\rangle,\left\langle w_{3}\right\rangle\right\rangle, \quad\left\langle\left\langle s, w_{1}, p_{0}\right\rangle,\left\langle q, w_{3}\right\rangle\right\rangle, \\
& \left\langle\left\langle w_{2}, p_{0}\right\rangle,\langle\rangle\right\rangle \quad\left\langle\left\langle s, w_{2}, p_{0}\right\rangle,\langle\rangle\right\rangle \quad\left\langle\left\langle s, w_{2}, p_{0}\right\rangle,\left\langle w_{1}\right\rangle\right\rangle, \quad\left\langle\left\langle s, w_{2}, p_{0}\right\rangle,\left\langle q, w_{1}\right\rangle\right\rangle, \\
& \left\langle\left\langle s, w_{2}, p_{0}\right\rangle,\left\langle w_{2}\right\rangle\right\rangle, \quad\left\langle\left\langle s, w_{2}, p_{0}\right\rangle,\left\langle q, w_{2}\right\rangle\right\rangle, \\
& \} \quad\} \quad\left\langle\left\langle s, w_{2}, p_{0}\right\rangle,\left\langle w_{3}\right\rangle\right\rangle\right\} \quad\left\langle\left\langle s, w_{2}, p_{0}\right\rangle,\left\langle q, w_{3}\right\rangle\right\rangle\right\}
\end{aligned}
$$

Table 4 Information states for (27), part one

The remainder of the updates for (27) are illustrated in Table 5 below.

The fourth update $\left[\mathrm{DIR}_{T \omega}\langle\mathrm{i}, \perp \Omega\rangle\right]$ checks for each pair (row) whether the speaker i has direct (witness) evidence for the at-issue proposition $\perp \Omega$ in the top world $T \omega$ of that row. If not, that pair is eliminated. Because the top worlds collectively form the context set $(T \omega \|)$, if all pairs containing a specific top world are eliminated, the context set is thereby reduced. Assuming $c_{3}$ above as the input, the output of this update is $c_{4}$ below. In the model in Figure $7, w_{1}$ is not a world where the speaker has direct evidence that Sandy won, but $w_{0}$ and $w_{2}$ are, so each pair with top world $w_{1}$ is eliminated. Thus, the context set $T \omega \|$ gets reduced to $\left\{w_{0}, w_{2}\right\}$ and now includes the information that the speaker has direct evidence that Sandy won. This is a direct update to the context set in two ways: there is no propositional discourse referent introduced for the evidential proposition

16 If there were more than one top individual $(T \delta)$, the introduction of a propositional discourse referent may be restricted by top individual ([p|p= $\left.=\perp \omega \|_{T \delta}\right]$ ), depending on what we want the at-issue proposition to be (see Murray 2010 on content questions, also van den Berg 1996 on restriction of states). 
Varieties of update

$\operatorname{DIR}(i, q)$ and there is no intermediate proposal update, as there is for the at-issue proposition, discussed below.

\begin{tabular}{llll}
\hline$c_{4}$ & $c_{5}$ & $c_{7}$ \\
\cline { 1 - 3 }$\left\{\left\langle\left\langle s, w_{0}, p_{0}\right\rangle,\left\langle q, w_{1}\right\rangle\right\rangle\right.$, & \{ & \{ & \{ \\
$\left\langle\left\langle s, w_{0}, p_{0}\right\rangle,\left\langle q, w_{2}\right\rangle\right\rangle$, & $\left\langle\left\langle s, w_{0}, p_{0}\right\rangle,\left\langle q, w_{2}\right\rangle\right\rangle$, & & \\
$\left\langle\left\langle s, w_{0}, p_{0}\right\rangle,\left\langle q, w_{3}\right\rangle\right\rangle$, & & & \\
$\left\langle\left\langle s, w_{2}, p_{0}\right\rangle,\left\langle q, w_{1}\right\rangle\right\rangle$, & & & \\
$\left\langle\left\langle s, w_{2}, p_{0}\right\rangle,\left\langle q, w_{2}\right\rangle\right\rangle$, & $\left\langle\left\langle s, w_{2}, p_{0}\right\rangle,\left\langle q, w_{2}\right\rangle\right\rangle$ & $\left\langle\left\langle s, w_{2}, p_{0}\right\rangle,\left\langle q, w_{2}\right\rangle\right\rangle$ & $\left\langle\left\langle p_{2}, s, w_{2}, p_{0}\right\rangle,\left\langle q, w_{2}\right\rangle\right\rangle$ \\
$\left.\left\langle\left\langle s, w_{2}, p_{0}\right\rangle,\left\langle q, w_{3}\right\rangle\right\rangle\right\}$ & \} & &
\end{tabular}

Table 5 Information states for (27), part two

The fifth update $[\perp \omega \in T \omega \|]$ represents the proposal to update with the at-issue proposition. ${ }^{17}$ It requires each (most prominent) bottom world $\perp \omega$ to be in the context set $T \omega \|$. The effect can be seen in $c_{5}$ : certain pairs (rows) have been eliminated, but no top worlds have been. Because this update does not predicate top worlds, no top world will be completely eliminated, even if all rows containing a certain bottom world are eliminated. ${ }^{18}$ Thus, the context set has not yet been updated; it is the same as in $c_{4}\left(=\left\{w_{0}, w_{2}\right\}\right)$. The resulting bottom worlds correspond to the darker gray area in Figure 7 : $q$-worlds in the context set are the proposed worlds to update to.

This fifth update represents a proposal in two ways. First, the bottom world column $(\perp \omega \|)$ is now the proposed context set. This is represented in the context (information state) before the actual context set is updated, an effect contributed by the next update. Second, this update significantly changes the structure of the information state, here by altering the dependencies between the top and bottom worlds. This is why I consider it a structuring update, distinct from the other varieties of update. In a system with representations of different participant's commitment sets (e.g., Gunlogson 2001, Farkas \& Bruce 2010), the proposal nature of the structuring update could be implemented more explicitly. The implementation here is somewhat implicit,

17 Another way of representing the proposal would be to use a higher order referent for relations between worlds or propositions, e.g., an ordering relation. However, instead of stating that there is a relation, I chose this formulation, which enforces a relation between worlds already present in the information state. This also minimizes the types of referents needed for the analysis. It does make necessary a separate propositional discourse referent for the entire at-issue proposition: after this update, the collection of the most prominent worlds in the bottom sequence is no longer the at-issue proposition - it is a subset of that proposition, the worlds that are both in the at-issue proposition and in the context set. 18 The only exception is if all worlds are eliminated, resulting in the empty (absurd) state. 
and does not require explicit acceptance by any interlocutor. It does, however, provide structure for subsequent denials, objections, and challenges to pick up on (both the propositional discourse referent and the proposed context set). No such structure is present for the not-at-issue content.

The penultimate update $[T \omega=\perp \omega]$ further reduces the context set to worlds where the proposed proposition is true. ${ }^{19}$ It requires for each row that the top world is identical to the most prominent bottom world. At this stage, these bottom worlds represent the proposed context set, so this update essentially accepts the proposal. I assume this update, like the previous one and the following one, is part of the contribution of declarative mood, and will be contributed for each declarative marked clause. The combined effect of this update and the last one is to add the at-issue proposition to the common ground. While both not-at-issue and at-issue information end up in the context set, only at-issue information has an intermediate proposal update and must be represented by a propositional discourse referent.

The final update ${ }^{\top}[p \mid p=T \omega \|]$ introduces a discourse referent for the new context set, now $\left\{w_{2}\right\}$. This is the modal re-centering update from Bittner 2011. This proposition representing the new, updated context set is now the most prominent member of the top sequence.

The definition of truth, given in Appendix A, draws on this representation of the context set. The truth conditions for (27) include both the not-at-issue information and the at-issue information, because the context set has been updated with both propositions. So, (27) is true in a model $\mathcal{M}$ and a world $w$ if and only if Sandy won in $w$ in $\mathcal{M}$ and the speaker has direct evidence that Sandy won in $w$ in $\mathcal{M}$. Thus, it can be false if Sandy didn't win or if the speaker does not have direct evidence that Sandy won. Unlike in prior analyses, here the evidential contribution is strictly part of the truth conditions - not a presupposition (cf. Matthewson, Rullmann \& Davis 2007, a.o.), not a sincerity condition (cf. Faller 2002). The difference between the evidential proposition and the proposition in the evidential's scope comes out as a difference in status, at-issue versus not-at-issue, and how that information is analyzed, not as a difference in truth conditionality. This difference in status also accounts for the direct challengeability facts. It is worth noting two final points on the proposed analysis of evidentials, which also apply to the phenomena discussed below. First, both contributions are new information added to the common ground. Second, and crucially, the evidential contribution will remain in the context set even if the at-issue proposition is denied.

19 This update differs slightly from Murray (2010), to better handle cross-sentential anaphora. 
Varieties of update

It is important to be clear that the given definition of truth is for sentences, and not for propositions alone. Propositions are still understood as sets of worlds, true in a world if and only if that world is in the proposition. A proposition can be true or false independent of whether or not a sentence proffering that proposition is true.

This analysis for the Cheyenne direct evidential in a declarative sentence illustrates the implementation of all three varieties of update: updates that introduce of discourse referents (nominal, modal, and propositional); direct updates to the common ground, which here predicate top worlds, the worlds that represent the context set; and structuring updates, which, in this system, significantly alter the structure of the information state.

What about other moods? As discussed in Section 2, I analyze all moods as contributing an illocutionary relation, updates that structure the context. For polar interrogatives, as in English (28) and Cheyenne (29), this is an update that partitions the worlds in the context set into the yes and no answers.

(28) Did Sandy win?

(29) É-hó'täheva-he Sandy?

$$
=(13)
$$
3-win-Y/N Sandy

'Did Sandy win?'

The updates for (28) and (29) are illustrated in Figure 8 and their translation is given in (30), assuming their meanings are parallel (but see Murray 2010). Figure 8 is Figure 2 with worlds added, providing the model used below.
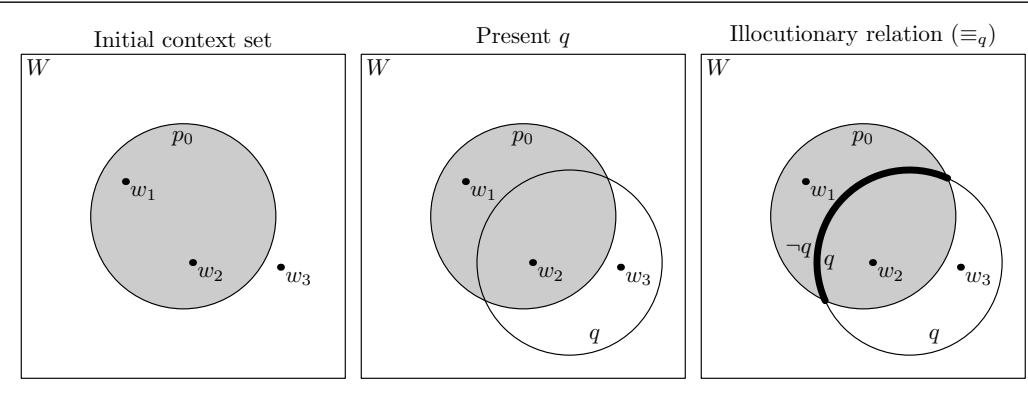

Figure 8 Updates for (28) and (29): polar interrogative mood

$$
\underbrace{{ }^{\top}[\mathrm{x} \mid \mathrm{x}=\text { sandy }] ;\left[\mathrm{w} \mid \text { won }_{\mathrm{w}}\langle\top \delta\rangle\right] ;[\mathrm{p} \mid \mathrm{p}=\perp \omega \|]}_{\text {(present at-issue proposition } q \text { ) }} ; \underbrace{\left[\mathrm{p} \mid \mathrm{p} \in{ }^{?} \perp \omega \|\right]}_{\text {(illocutionary relation) }}
$$


The first three updates in (30) are the same as for the declarative (27): they have the same at-issue proposition, but different moods. Information states for (30) are given in Table 6, assuming the model in Figure 8 and the initial state $c_{0}$, where the initial context set is $p_{0}=\left\{w_{1}, w_{2}\right\}$. The remaining states correspond sequentially to the updates in (30).

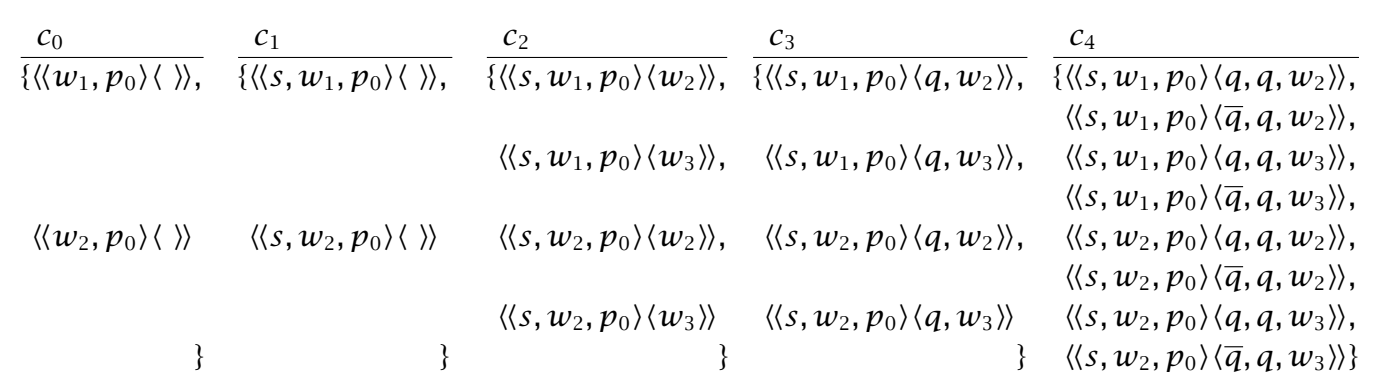

Table 6 Example information states for (30)

The illocutionary relation update $\left[\mathrm{p} \mid \mathrm{p} \in{ }^{?} \perp \omega \|\right]$, illustrated in $c_{4}$, introduces a propositional referent for the answers, $q, \bar{q}$, incorporating Hamblin 1973. This induces a partition on the information state, incorporating Groenendijk \& Stokhof $1984 .{ }^{20}$ Unlike in $c_{3}$, in $c_{4}$ there are now two important substates of the information state: the set of rows where the most prominent bottom world is $q$, the yes answer, and the set where it is $\bar{q}$, the no answer. ${ }^{21}$ This implementation of the structuring update does not eliminate rows, as in the structuring update for declarative mood. But it does significantly alter the structure of the context by inducing a partition, resulting in two substates representing the answers.

No information is gained in the sequence of updates in (30): no worlds are eliminated from the context set. A truth value will not be defined for (30) because it does not introduce a proposition into the top sequence. Some questions contain new not-at-issue content, which could still directly update the context set (directly eliminate top worlds). However, no new context set referent would be introduced, as this is an effect of declarative mood.

20 To more explicitly encode a partition, and for a more explicit similarity with other structuring updates, the following two updates could be added to the illocutionary relation for polar interrogative mood: $[w \mid w \in \perp \Omega] ;[\perp \omega=\top \omega]$. These updates are also useful for analyzing hedged questions, but are not included above for the sake of space and simplicity.

21 Actually answering yes or no is more complicated (see, e.g., Murray 2010, Farkas \& Bruce 2010, and Brasoveanu, Farkas \& Roelofsen 2012 ). 
Varieties of update

On this view, all moods contribute structuring updates. The present paper does not discuss imperatives, but they could be analyzed as imposing a preference relation on the context, following Starr 2010. Like polar interrogatives, plain imperatives do not add information to the context set.

Not only does the proposed analysis allow a unified treatment of different kinds of moods, it allows a unified treatment of declarative mood, even when the assertion is hedged. One example of this is Cheyenne sentences with the reportative evidential: declarative sentences that do not commit the speaker at all to the at-issue proposition. I take this to be a kind of hedge: the commitment to the at-issue proposition is reduced or, in this case, removed. Consider Cheyenne (31), which, parallel to the direct evidential (26), makes three semantic contributions: an update that introduces a discourse referent for the at-issue proposition, a direct update (not-at-issue restriction), and a structuring update (illocutionary relation). $\mathrm{My} \mathrm{UC}_{\omega}$ translation for (31) is (32).

$$
\begin{aligned}
& \text { É-hó'täheva-séstse Sandy. } \\
& \text { 3-win-RPT.3SG Sandy } \\
& \text { 'Sandy won, I hear.' }
\end{aligned}
$$

$$
\begin{aligned}
& \underbrace{{ }^{\mathrm{T}}[\mathrm{x} \mid \mathrm{x}=\text { sandy }] ;\left[\mathrm{w} \mid \text { won }_{\mathrm{w}}\langle\mathrm{T} \delta\rangle\right] ;[\mathrm{p} \mid \mathrm{p}=\perp \omega \|]}_{\text {(present at-issue proposition } q)} ; \underbrace{\left[\mathrm{RPT}_{T \omega}\langle\mathrm{i}, \perp \Omega\rangle\right]}_{\text {(not-at-issue restriction) }} ; \\
& \underbrace{[\mathrm{w} \mid \mathrm{w}=\top \omega]}_{\text {(RPT commitment) }} ; \quad \underbrace{[\perp \omega \in \top \omega \|] ;[\top \omega=\perp \omega]}_{\text {(illocutionary relation) }} ; \underbrace{{ }^{\mathrm{T}}[\mathrm{p} \mid \mathrm{p}=\top \omega \|]}_{\text {(new context set) }}
\end{aligned}
$$

The at-issue proposition updates in (32) are the same as for the polar interrogative (30) and the declarative with a direct evidential (27). Also like the direct evidential, the reportative contributes a not-at-issue restriction, which directly updates the context set to worlds where the speaker has the specified kind of evidence for the at-issue proposition.

The fifth update $[w \mid w=T \omega]$ is new for the reportative. It is the hedge. It introduces worlds into the bottom sequence for the proposition the reportative commits the speaker to. For Cheyenne (31), this is just the current context set, representing the fact that the speaker is not committed at all to the truth of the at-issue proposition. ${ }^{22}$ This hedge update alters what the most prominent bottom worlds $(\perp \omega)$ are, thus altering what the argument of

22 Alternatively, the reportative commitment could introduce all worlds. However, the remaining updates would cause the output state to be the same as the output for (32). 
the illocutionary relation is. All hedges will involve this type of update, but what proposition is introduced will differ. ${ }^{23}$

The illocutionary relation and new context set updates are the same for the reportative (32) and the direct (27). These three updates are contributed by the declarative mood, no matter what the force of assertion is. They structure the context, representing the proposal to add a proposition to the context set, and add a new referent for the updated context set.

This analysis also works for the reportative evidential in interrogatives, which would be translated with the first 5 updates of (32) and the illocutionary relation for the polar interrogative mood from (30). This captures the fact that evidentials and other hedges in questions, e.g., Did Sandy win, reportedly? can affect the force of the possible answers: Yes means (can mean) Yes, Sandy won reportedly not Yes, Sandy won (see Murray 2010).

Because the Cheyenne reportative does not commit the speaker at all to the at-issue proposition, the at-issue proposition can be explicitly denied, as in (33), repeated from (15) above.

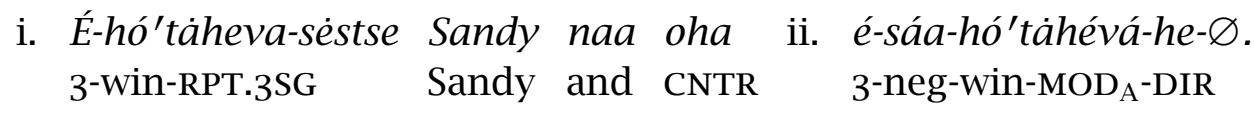

'(i) Sandy won, they say, but (ii) (I was there and) she didn't.'

This can be translated into $\mathrm{UC}_{\omega}$ as (34), which is just (32) for the first conjunct and (27) for the second, with a slightly different at-issue proposition: $\neg q$. Conjunction is treated as sequential update; I have not incorporated any meaning for the contrastive component of the conjunction.

$$
\begin{aligned}
& \text { i. } \underbrace{\mathrm{T}}[\mathrm{x} \mid \mathrm{x}=\text { sandy }] ;\left[\mathrm{w} \mid \mathrm{won}_{\mathrm{w}}\langle\mathrm{T} \delta\rangle\right] ;[\mathrm{p} \mid \mathrm{p}=\perp \omega \|] ; \underbrace{\left[\mathrm{RPT}_{T \omega}\langle\mathrm{i}, \perp \Omega\rangle\right]} ; \\
& \text { (present at-issue proposition } q \text { ) (not-at-issue restriction) } \\
& \underbrace{[\mathrm{w} \mid \mathrm{w}=\mathrm{T} \omega] ;}_{\text {(RPT commitment) }} \quad \underbrace{[\perp \omega \in T \omega \|] ;[\top \omega=\perp \omega]}_{\text {(illocutionary relation) }} ; \quad \underbrace{{ }^{\mathrm{T}}[\mathrm{p} \mid \mathrm{p}=\top \omega \|]}_{\text {(new context set) }} \\
& \text { ii. } \underbrace{\left[\mathrm{w} \mid \text { won }_{\mathrm{w}}\langle T \delta\rangle\right] ;[\mathrm{w} \mid \mathrm{w} \notin \perp \omega] ;[\mathrm{p} \mid \mathrm{p}=\perp \omega \|]}_{\text {(present at-issue proposition } \neg q)} ; \underbrace{\left[\mathrm{DIR}_{\top \omega}\langle\mathrm{i}, \perp \Omega\rangle\right]}_{\text {(not-at-issue restriction) }} ;
\end{aligned}
$$

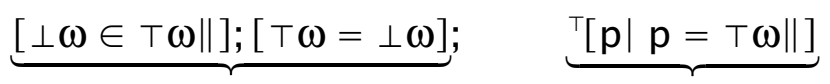

23 This type of update could be used for all sentences, not just hedges. For sentences that fully commit the speaker to the at-issue proposition, it could just reintroduce the worlds in the at-issue proposition, which are currently the bottom worlds, e.g., $[w \mid w=\perp \omega]$. 
Varieties of update

In the second conjunct, the at-issue proposition is that Sandy didn't win. Because the Cheyenne verb is repeated, I have included the $\left[w \mid w_{w}\left\langle n_{w}\langle T\rangle\right]\right.$ update again, though those worlds have already been introduced and this update could be left out. The next update $[w \mid w \notin \perp \omega]$ introduces the complement of those worlds, the effect of negation (as in Stone \& Hardt 1999).

The updates in (34) are compatible: they have an output state. The truth conditions for (34) are that the speaker has reportative evidence that Sandy won, that the speaker has direct evidence that Sandy did not win, and that Sandy did not win.

\subsection{Parentheticals and appositives}

The implementation developed in the previous section allows for a unified analysis of mood as well as an analysis of how hedges affect the contribution of mood. This can be directly extended to evidential parentheticals in English, as well as other kinds of hedges, e.g., ones involving sentential adverbs.

First, consider (35), a plain English sentence with declarative mood. This contributes the at-issue proposition updates and the updates for declarative mood. This general analysis is illustrated in Figure 4 in Section 2 above. My translation of (35) into $\mathrm{UC}_{\omega}$ is (36).

(35) Floyd won (the race).

$$
\begin{aligned}
& \underbrace{{ }^{\top}[\mathrm{x} \mid \mathrm{x}=\text { floyd }] ;\left[\mathrm{w} \mid \text { won }_{\mathrm{w}}\langle\mathrm{T} \delta\rangle\right] ;[\mathrm{p} \mid \mathrm{p}=\perp \omega \|]}_{\text {(present at-issue proposition } q)} ; \\
& \underbrace{[\perp \omega \in T \omega \|] ;[\top \omega=\perp \omega] ;}_{\text {(illocutionary relation) }} \quad \underbrace{{ }^{\top}[p \mid p=T \omega \|]}_{\text {(new context set) }}
\end{aligned}
$$

This translation follows directly from the implementation in Section 3.1 above. The at-issue proposition updates are the same as for, e.g, the Cheyenne direct (26), with the subject changed to Floyd. The declarative mood also contributes the same updates: the illocutionary relation and the new context set. There is no new not-at-issue content, so there is no not-at-issue restriction, no direct update. The truth conditions for (36) are that Floyd won.

Evidential parentheticals, as in English (37), both contribute a not-at-issue restriction and hedge the assertion, parallel to the Cheyenne reportative (31). 
Unlike the Cheyenne reportative, (37) requires that the at-issue proposition $q$ be at least possible (see Section 2). The translation of (37) into $\mathrm{UC}_{\omega}$ is (38).

(37) Floyd won (the race), I hear.

$$
\begin{aligned}
& \underbrace{{ }^{\mathrm{T}}[\mathrm{x} \mid \mathrm{x}=\text { floyd }] ;\left[\mathrm{w} \mid \mathrm{won}_{\mathrm{w}}\langle\top \delta\rangle\right] ;[\mathrm{p} \mid \mathrm{p}=\perp \omega \|]}_{\text {(present at-issue proposition } q \text { ) }} ; \underbrace{\left[\text { heard }_{T \omega}\langle\mathrm{i}, \perp \Omega\rangle\right]}_{\text {(not-at-issue restriction) }} ; \\
& \underbrace{[\mathrm{w} \mid \mathrm{w} \in \diamond \perp \Omega]}_{\text {(hedged commitment) }} ; \quad \underbrace{[\perp \omega \in \top \omega \|] ;[\top \omega=\perp \omega]}_{\text {(illocutionary relation) }} ; \underbrace{\mathrm{T}^{[\mathrm{p} \mid \mathrm{p}=\top \omega \|]}}_{\text {(new context set) }}
\end{aligned}
$$

The translation in (38) has two updates in addition to (36). The fourth update [heard $\left.{ }_{T \omega}\langle\mathrm{i}, \perp \Omega\rangle\right]$ is a not-at-issue restriction, which directly updates the context set with the information that the speaker heard the at-issue proposition $q$. This is parallel to the not-at-issue restriction for the Cheyenne reportative (32), but with slightly different content, to allow for differences in meaning between the Cheyenne (grammatical) evidential and the English (lexical) verb in the parenthetical. The fifth update $[w \mid w \in \diamond \perp \Omega]$ is the hedge: it introduces the proposition that the speaker is committed to, here, that the at-issue proposition is possible $\nabla q\left(\nabla_{\perp}\right)$ ). (For the purposes of this paper, I remain neutral on the particular modal semantics, but assume a proposition $\checkmark q$ can be defined.) The truth conditions for (38) are that the speaker heard that Floyd won and that it is possible that Floyd won.

Though there is less of a commitment to the at-issue proposition in (37) than in (35), the declarative mood updates remain the same. Because referents are ordered by salience in $\mathrm{UC}_{\omega}$, when the evidential parenthetical introduces worlds into the bottom sequence $\left[\mathrm{w} \mid \mathrm{w} \in \diamond_{\perp} \Omega\right.$ ], this changes what the argument of the illocutionary relation $\perp \omega$ refers to: the bottom worlds are now $\diamond q$-worlds, not $q$-worlds. That's the hedge. No "illocutionary modifiers" are necessary. It is just a difference in discourse reference.

Unlike evidential parentheticals, appositives as in (39) do not alter the force of an assertion. They just contribute not-at-issue information, treated here as directly updating the context set (see Figure 6). The implementation of these updates directly follows from the analyses of the phenomena above. The $\mathrm{UC}_{\omega}$ translation of (39) is given in (40), where I abstract away from the complexities of the predicate to focus on the semantic effect of the appositive.

(39) Tivi, who is a cat, likes to chase her tail. $=(23)$ 
Varieties of update

$$
\begin{aligned}
& \text { (present at-issue proposition } q \text { ) }
\end{aligned}
$$

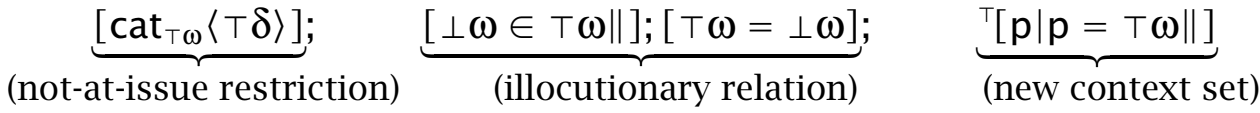

The appositive contributes the fourth update, $\left[\operatorname{cat}_{\top \omega}\langle T \delta\rangle\right]$. Sentence (39) without the appositive would have the same translation without this fourth update. I've put the updates in this order for comparison with earlier examples, but the appositive update could occur any time after the first update, which provides the referent for Tivi. The truth conditions for (40) are that Tivi is a cat and that Tivi likes to chase her tail.

As in del Gobbo 2007 and Nouwen 2007, on the proposed analysis the appositive contributes an open proposition that is anaphorically linked $(\top \delta)$ to the appositive's anchor, here Tivi. The appositive is also anaphorically linked to worlds, here the worlds in the context set $(T \omega)$, so it can update them directly. This provides an avenue of analysis for semantically embedded appositives, as in Joan believes that her chip, which was installed last month, has a twelve year guarantee (Amaral, Roberts \& Smith 2007). Such appositives can be analyzed as anaphoric to the worlds introduced by the matrix verb, e.g., believe.

The difference in the not-at-issue restriction for an appositive as compared to an evidential is that the appositive content is not related to the at-issue proposition. It just adds information about an individual, in (40) that the subject, Tivi, is a cat $\left[\mathrm{cat}_{\top \omega}\langle T \delta\rangle\right]$. An evidential restriction, on the other hand, is a relation between the speaker and the at-issue proposition, e.g., [heard $\left.\operatorname{T\omega }_{\top \omega}\langle\mathrm{i}, \perp \Omega\rangle\right]$ for (38). Evidential restrictions in some languages can shift in embedded clauses, becoming anchored to the matrix subject instead of the speaker. This could be analyzed as a difference in the type of indexical argument, that is, how $\mathrm{i}$ is interpreted in [heard $\left.\mathrm{T}_{\mathrm{T}}\langle\mathrm{i}, \perp \Omega\rangle\right]$.

Though not explicitly illustrated by (39), the proposed analysis can account for anaphora in and out of not-at-issue content (see, e.g., Nouwen 2007, Amaral, Roberts \& Smith 2007, AnderBois, Brasoveanu \& Henderson 2010, Lee 2011). In fact, each $\mathrm{UC}_{\omega}$ translation above provides examples. In (40), the referent for Tivi, introduced as part of the at-issue content, is referred to in the not-at-issue restriction (the $T \delta$ in $\left[\mathrm{cat}_{\top \omega}\langle\top \delta\rangle\right]$ ). A referent could be introduced in the appositive and referred to in the at-issue content. This would just be analyzed as a standard update that introduces an individual discourse referent. Furthermore, there is anaphora to the at-issue content in 
the illocutionary relation, which is technically neither at-issue or not-at-issue information (as that is a propositional distinction). On this implementation, all three varieties of update interact because they are incorporated into the same semantic representation.

So, there can be anaphoric dependencies between the at-issue and notat-issue content, and subsequent anaphora to things introduced in, e.g., an appositive. However, the not-at-issue proposition itself, what is directly added to the context set, is not directly available for propositional anaphora in subsequent discourse. On this analysis, no propositional discourse referent is introduced for the entire not-at-issue proposition, in (40) the proposition that Tivi is a cat, and no structuring update operates on this proposition. This is supported by direct challengeability tests, at least for medial appositives (see, e.g., AnderBois, Brasoveanu \& Henderson 2010, Koev 2012). Though not directly accessible, the not-at-issue information is still present and recoverable.

\subsection{Summary}

This section has provided an implementation in $\mathrm{UC}_{\omega}$ of the analysis presented in Section 2. $\mathrm{UC}_{\omega}$ is a dynamic semantic system that uses pairs of sequences to model centering based anaphora across domains. I used the distinction between the top and bottom sequence to model the difference between notat-issue and at-issue information while tracking truth conditional content.

The proposed three varieties of update have been implemented in $\mathrm{UC}_{\omega}$ as follows. Direct updates to the common ground are treated as updates that predicate top worlds, directly adding information to the context set without being first proposed. Structuring updates are updates that significantly alter the structure of the information state, as in inducing a partition or representing the proposed context set before updating to it. Updates that introduce discourse referents are updates that introduce objects of various types (individuals, worlds, propositions) into either the top or bottom sequence. In particular, a referent for the at-issue proposition is always introduced into the bottom sequence. (Not-at-issue information need not have a referent.)

Table 7 summarizes the implementation of the above data, organized by morpheme/construction. It shows that we can compositionally assign meaning to these phenomena while accounting for their interactions. 
Varieties of update

\begin{tabular}{|c|c|}
\hline & Updates \\
\hline At-issue proposition & ${ }^{\top}[\mathrm{x} \mid \mathrm{x}=\mathrm{sandy}] ;\left[\mathrm{w} \mid \mathrm{won}_{\mathrm{w}}\langle\top \delta\rangle\right] ;[\mathrm{p} \mid \mathrm{p}=\perp \omega \|]$ \\
\hline Cheyenne direct evidential & {$\left[\mathrm{DIR}_{T \omega}\langle\mathrm{i}, \perp \Omega\rangle\right]$} \\
\hline Cheyenne reportative evidential & {$\left[\mathrm{RPT}_{T \omega}\langle\mathrm{i}, \perp \Omega\rangle\right] ;[\mathrm{w} \mid \mathrm{w}=\mathrm{T} \omega]$} \\
\hline English evidential parenthetical & heard $\left._{T \omega}\langle\mathrm{i}, \perp \Omega\rangle\right] ;[\mathrm{w} \mid \mathrm{w} \in \diamond \perp \Omega]$ \\
\hline English appositive & {$\left[\operatorname{redhead}_{T \omega}\langle T \delta\rangle\right]$} \\
\hline Declarative mood & {$[\perp \omega \in \top \omega \|] ;[\top \omega=\perp \omega] ;{ }^{\top}[p \mid p=\top \omega \|]$} \\
\hline Interrogative mood & {$[p \mid p \in ? \perp \omega \|]$} \\
\hline
\end{tabular}

Table $7 \quad$ Summary: updates contributed by various phenomena

I assume that the updates for the at-issue proposition are introduced by the name and the verb. The third of these updates, which introduces the propositional discourse referent for the at-issue proposition, could also be attributed to the (tensed) verb.

This raises a question: what introduces a propositional discourse referent? In what I've proposed here, at-issue information is always represented by a propositional discourse referent while not-at-issue information may or may not be (see also Murray 2010). For all of the phenomena analyzed above, not-at-issue information is not represented by a discourse referent. However, some constructions may introduce multiple propositional discourse referents, such as sentences with embedding verbs (see the discussion of (16) and (17) in Section 2.1), and sentences with modals, discussed briefly at the end of section 4 below. For sentences that introduce multiple propositional referents, various factors, including context, will determine which is at-issue. So, while this paper argues that certain constructions contributing not-at-issue content should not introduce a discourse referent, a study of propositional anaphora across a wider variety of constructions is needed.

\section{Discussion of related approaches and prospects}

In this section, I discuss some existing analyses that distinguish similar varieties of update or that in general attempt to account for a similar range of phenomena. There are many specific analyses of the phenomena discussed in this paper, in particular evidentials (see, e.g., Faller 2002, Matthewson, Rullmann \& Davis 2007, Murray 2009, 2010, Lee 2011, among many others) and appositives (see, e.g., Potts 2005, Nouwen 2007, Schlenker 2010, Ander- 
Bois, Brasoveanu \& Henderson 2010, among others). However, the goal of this section is not to compare details of analyses of particular phenomena. Instead, I seek to bring out similar general distinctions that have been made in the literature, discuss the similarities and differences in approach and empirical coverage, and explore some potential extensions of the analysis developed in this paper.

A difference between updates of information and updates of attention is present in Update with Centering (Bittner 2009, 2011) as well as Inquisitive Semantics (e.g., Ciardelli, Groenendijk \& Roelofsen 2009). Updates of information reduce the context set while updates of attention introduce discourse referents or distinguish possibilities. Using this terminology, my direct updates are updates of information and updates that introduce discourse referents are updates of attention. However, structuring updates do not fit neatly into either of these categories. Structuring updates alter the relations between existing referents, but do not update the context set or just introduce discourse referents. The effects of these three varieties of update are intuitively distinct, and should be formally distinguished. In addition to these varieties of update, it is crucial to distinguish at-issue and not-at-issue information. These distinctions are not present in Update with Centering (Bittner 2009, 2011) or Inquisitive Semantics (Groenendijk \& Roelofsen 2009, Ciardelli, Groenendijk \& Roelofsen 2009), though, of course, they can be added, as this paper does for Update with Centering.

Some systems do distinguish between at-issue and not-at-issue content, and treat not-at-issue content as direct updates to the common ground (Murray 2009, 2010, AnderBois, Brasoveanu \& Henderson 2010). Murray 2009 presents an analysis of evidentials where at-issue and not-at-issue content are part of the same meaning dimension, but distinguished by how they update the common ground. The analysis is not dynamic and does not represent anaphora, so fails to account for much of the data discussed here. However, it is developed into an update semantics in Murray 2010, built on here.

To analyze appositives and their robust anaphoric interdependencies, AnderBois, Brasoveanu \& Henderson 2010 develops an analysis where at-issue and not-at-issue content are part of the same dimension of meaning, differing in how they update the context (direct vs. proposed update). The analysis, like the one discussed in this paper, is dynamic and the at-issue and not-atissue updates are not strictly ordered. AnderBois, Brasoveanu \& Henderson 2010 uses a propositional variable $p^{c s}$ whose value can be the current context set or any of its non-empty subsets. Not-at-issue information directly updates 
Varieties of update

this by eliminating any assignment to $p^{c s}$ that contains a world where the not-at-issue information is false. At-issue information contributes a proposal $p$ to restrict $p^{c s}$ to a subset $p \subseteq p^{c s}$. If the proposal is accepted, the context set is updated to $p \subseteq p^{c s}$.

Though the analysis in AnderBois, Brasoveanu \& Henderson 2010 and the one developed here share much in spirit and implementation, there are key differences in both details and empirical coverage. First, in AnderBois, Brasoveanu \& Henderson 2010 the proposal $p$ is a subset of the context set $p^{c s}$. Thus, there is no representation of the entire at-issue proposition, which can contain worlds outside of the context set. This is needed for propositional anaphora to the at-issue content and for the analysis of evidentials, hedges, and mood. Second, it isn't clear how to extend the AnderBois, Brasoveanu \& Henderson 2010 analysis to other moods. This is a benefit of the structuring updates proposed in this paper, the illocutionary relations contributed by mood markers, which use a proposition to induce structure on the context. A proposal is just one kind of structuring update. This allows not only a unified analysis of illocutionary moods, but a unified analysis of declarative mood, even for sentences containing hedges.

A related system is that in McCready 2010, which builds on Potts 2005 to analyze cases of mixed content (expressions that contribute both notat-issue and at-issue information) and cases where expressive meaning is primary. Extending Potts 2005, McCready 2010 defines a system of different logical types for different kinds of content: at-issue types, CI types, shunting types, and functional types for mixed content. However, McCready 2010 does not discuss how the different types of content are added to the common ground. On the current analysis, the distinction in varieties of update is crucial for analyzing hedges, giving evidentials the same semantic types, and unifying a treatment of mood. Another open issue is how to integrate McCready 2010 with a theory of anaphora; as many authors have discussed, this is important for understanding the interaction of at-issue and not-atissue content (Nouwen 2007, Amaral, Roberts \& Smith 2007, AnderBois, Brasoveanu \& Henderson 2010, Lee 2011).

The semantics of mood has been the topic of many other recent works, including Portner 2004, Groenendijk \& Roelofsen 2009, Farkas \& Bruce 2010, Starr 2010, and Bittner 2011. Farkas \& Bruce 2010 analyzes assertions and polar questions, arguing in depth for the treatment of assertion as a proposal to update the common ground with the asserted proposition $p$ and for polar questions as proposals to update with either $p$ or $\neg p$ (see also Groenendijk 
\& Roelofsen 2009). Farkas \& Bruce 2010 does not discuss a treatment of not-at-issue content, though this could be added. In the current paper, I have analyzed both the proposal component of assertion and the uptake of the proposed information as part of the contribution of declarative mood. These updates provide the structure needed for subsequent discourse moves, while providing significant empirical coverage and an intuitive definition of truth for a sentence. A further parallel exists for polar questions, which here introduce a referent for each answer. This effect could be construed as a request for an answer, or a proposal to update with one. As implemented in this paper, these are all represented as part of the same dimension of context, the sequences of discourse referents and the structure between them.

A prospect for extending the current analysis, in addition to the phenomena discussed in McCready 2010, is (epistemic) modals, which have been analyzed as evidential markers of indirect inference (von Fintel \& Gillies 2007, 2010). However, at least two differences between modals and evidentials must be addressed, both of which could be incorporated in the current system. First, roughly in my terms, an English sentence with an epistemic modal, such as the von Fintel \& Gillies 2007 example There might be two reds, can be analyzed as involving three propositions: the prejacent proposition, $q$, that there are two reds, the modal proposition $\diamond q$, and an evidential proposition about indirect evidence for $q$, $\operatorname{IND}(q)$ (abstracting away from the anchor of the evidence). Both $q$ and $\diamond q$ are directly challengeable, depending on the context (von Fintel \& Gillies 2007), and so have variable at-issue status, parallel to the embedding verb examples (16) and (17) discussed above. A propositional discourse referent would be introduced for each of these propositions; which is at-issue would be determined by context. The third proposition, $\operatorname{IND}(q)$, is not directly challengeable. It must be not-at-issue and would be analyzed as a not-at-issue restriction, as in the evidential and parenthetical examples discussed above. However, for Cheyenne evidentials and English evidential parentheticals only two propositions are involved: the at-issue proposition $q$ and the evidential proposition $\operatorname{EV}(q)$. There is no modal proposition that can be challenged, supported by the infelicity of \#That's right, there might be as a response to There are two reds, I hear.

Second, there are contexts where indirect evidentials are felicitous, but English epistemic modals, e.g., must, are not. For example, consider a context where we work in a building with no windows. We are going to meet in your office and head out to lunch. On my way, I see a man enter the hallway. He has an umbrella, rain jacket, and is dripping wet. In this context, I can say to 
Varieties of update

myself, or someone else in the hallway It must be raining. I could also use, e.g., the Cheyenne indirect (conjectural) evidential here (Murray 2010). I leave the hallway and enter your office. You have not seen the drenched person in the hallway. You ask What's the weather like?, considering whether to bring a coat, umbrella. In this context, the response It must be raining is infelicitous. In contrast, the, e.g., Cheyenne indirect evidential must be used here. This could be captured by analyzing English must as not merely requiring that the speaker have indirect evidence, but also that the evidence be accessible, perhaps anaphorically, akin to English therefore (following Stone 1994).

\section{Conclusion}

Synthesizing several ideas from the current semantics literature, this paper has argued that distinguishing three varieties of update - direct updates, structuring updates, and updates that introduce discourse referents - has wide empirical coverage. Every sentence potentially contributes these three kinds of update: an update that introduces a discourse referent for the at-issue proposition; a direct update, the not-at-issue restriction (if there is any not-at-issue content); and a structuring update, the illocutionary relation, which is contributed by mood. Each of these contributions is new to the context: new discourse referents, new information, new structure. Though separate kinds of semantic contributions, all can be compositionally integrated into a single semantic representation.

Distinguishing these three varieties of update, and making explicit the different semantic contributions of every sentence, allows for a unified analysis of sentences with different types of evidentials and evidential parentheticals, a related analysis of supplemental comments that do not affect sentential force (appositives), and a unified analysis of the semantic contributions of mood, even for sentences containing hedges.

The proposed analysis brings out the common properties of what have previously been considered disparate phenomena, each of which presents significant difficulties for analysis. While not given identical treatments, various expressions crosslinguistically can be analyzed using the same suite of tools: different varieties of update used to model different semantic contributions of natural language phenomena. 


\section{A Appendix: Update with Modal Centering $\left(\mathrm{UC}_{\omega}\right)($ Bittner 2011)}

Complete definitions for $\mathrm{UC}_{\omega}$ are given below, with minimal variation from Bittner 2011 (but added discussion): the type theory (in A.1) and the DRS expressions that abbreviate the type-theoretic expressions (in A.2, following Muskens 1996, Stone 1999, a.o., adapting, e.g., Kamp 1981, Kamp \& Reyle 1993). One addition made to the system is discussed in A.3.

\section{A.1 Type theory}

A $\mathrm{UC}_{\omega}$ information state is the characteristic function of a set of pairs of sequences. Each pair, or $T \perp$-list, is composed of a top $(T)$ sequence and a bottom $(\perp)$ sequence.

Definition 1 (lists and info-states). Given a non-empty set $D$ of objects:

i. $D^{n, m}=D^{n} \times D^{m}$ is the set of $T \perp$-lists of $n$ T-objects $m \perp$-objects

ii. For any $\top \perp$-list $i \in D^{n, m}, \top i:=i_{1}$ and $\perp i:=i_{2}$. Thus, $i=\langle\top i, \perp i\rangle$.

iii. An $(n, m)$-info-state is (the characteristic function of) any subset of $D^{n, m}$. The empty set, $\varnothing$, is the absurd state.

Basic $\mathrm{UC}_{\omega}$ types are individuals $(\delta)$, worlds $(\omega)$, truth values $(t)$, and $\top \perp$ lists $(s)$. The domain of $T \perp$-lists $\left(D_{s}\right)$ consists of all the pairs of sequences of objects of discourse referent types - individuals, worlds, and propositions $(\Omega:=\omega t)$ - including the empty $T \perp$-list $\langle\langle\rangle,\langle\rangle\rangle$. A model for $\mathrm{UC}_{\omega}$ consists of a $\mathrm{UC}_{\omega}$-frame and an interpretation of non-logical constants.

Definition 2 ( $\mathrm{UC}_{\omega}$ types). The set of $\mathrm{UC}_{\omega}$ types $\Theta$ is the smallest set such that: (i) $\delta, \omega, t, s \in \Theta$, and (ii) $(a b) \in \Theta$ if $a, b \in \Theta$.

- The subset $\operatorname{DR}(\Theta)=\{\delta, \omega, \omega t\}$ is the set of discourse referent types within $\Theta$

- For any type $a \in \Theta, \operatorname{Var}_{a}$ is the set of variables of type $a$ and $\operatorname{Con}_{a}$ the set of non-logical constants of type $a$

Definition 3 (UC $\mathrm{UC}_{\omega}$ frames). $\mathrm{A} \mathrm{UC}_{\omega}$ frame is a set $\left\{D_{a} \mid a \in \Theta\right\}$ of non-empty pairwise disjoint sets $D_{a}$ such that:

i. $D_{t}=\{1, \mathrm{O}\}$,

ii. $D_{(a b)}=\left\{f \mid \varnothing \subset \operatorname{Dom} f \subseteq D_{a} \& \operatorname{Ran} f \subseteq D_{b}\right\}$, and

iii. $D_{s}=\cup\left\{D^{n, m} \mid 0 \leq n \& 0 \leq m\right\}$, where $D=\cup\left\{D_{a} \mid a \in \operatorname{DR}(\Theta)\right\}$

Definition 4 (UC $\mathrm{UC}_{\omega}$ models). A $\mathrm{UC}_{\omega}$ model is a pair $\mathcal{M}=\left\langle\left\{D_{a} \mid a \in \Theta\right\}, \llbracket \cdot \rrbracket\right\rangle$ such that $\left\{D_{a} \mid a \in \Theta\right\}$ is a $\mathrm{UC}_{\omega}$ frame and for all $A \in \operatorname{Con}_{a}, \llbracket A \rrbracket \in D_{a}$. 
Varieties of update

The syntax and semantics of $\mathrm{UC}_{\omega}$ combines six standard rules (i - vi) and three centering rules (vii - ix). Rule (vii) builds extended $T \perp$-lists, interpreted as adding an object to the specified sequence of the input $T \perp$-list. Rule (viii) builds local (or row-wise) anaphors, e.g., $T a_{n}$ for the $n$th object of type $a$ in the top sequence of the input $T \perp$-list. Rule (ix) builds global (or column-wise) anaphors, e.g., $T a_{n}\left\{I_{s t}\right\}$ for the set of $T a_{n}$-objects from all the $T \perp$-lists of the input state $I$, adapting van den Berg 1996.

Definition 5 (UC $\omega_{\omega}$ syntax). For any type $a \in \Theta$, define the set of $a$-terms, Term ${ }_{a}$ :

i. $\operatorname{Con}_{a} \cup \operatorname{Var}_{a} \subseteq$ Term $_{a}$

ii. $\lambda u_{a}(B) \in$ Term $_{a b}, \quad$ if $u_{a} \in \operatorname{Var}_{a}$ and $B \in$ Term $_{b}$

iii. $B A \in$ Term $_{b}$, if $B \in$ Term $_{a b}$ and $A \in$ Term $_{a}$

iv. $(A=B) \in$ Term $_{t}$, if $A, B \in$ Term $_{a}$

v. $\neg \phi,(\phi \rightarrow \psi),(\phi \wedge \psi),(\phi \vee \psi) \in$ Term $_{t}$, if $\phi, \psi \in$ Term $_{t}$

vi. $\forall u_{a} \phi, \exists u_{a} \phi \in$ Term $_{t}$, if $u_{a} \in \operatorname{Var}_{a}$ and $\phi \in$ Term $_{t}$

vii. $\left(u_{a}^{\top} \oplus B\right),\left(u_{a}^{\perp} \oplus B\right) \in$ Term $_{s}$, if $a \in \mathrm{DR}(\Theta), u_{a} \in \operatorname{Var}_{a}$, and $B \in$ Term $_{s}$

viii. $T a_{n}, \perp a_{n} \in$ Term $_{s a}$, if $a \in \mathrm{DR}(\Theta)$ and $n \geq 1$

ix. $A\{B\} \in$ Term $_{a t}$, if $a \in \mathrm{DR}(\Theta), A \in$ Term $_{s a}$, and $B \in$ Term $_{s t}$

[Five notes on the metalanguage notation used below: (i) ' $X \doteq Y$ ' is used for ' $X$ is $Y$, if $Y$ is defined, else $X$ is undefined'. (ii) The von Neumann definition of truth values is used, so $1:=\{\varnothing\}$ and $0:=\varnothing$. (iii) For any sequence $z,(z)_{a}$ is the sub-sequence of type $a$ coordinates of $z$ and $(z)_{n}$ is the $n$th coordinate of $z$. (iv) For any object $d$ and sequence $z,(d \oplus z):=$ $\left\langle d, z_{1}, \ldots, z_{n}\right\rangle$. (v) ${ }^{\{} X$ is the set characterized by the function $X,{ }^{x} Y$ the characteristic function of the set $Y$.]

Definition 6 (UC $\mathrm{UC}_{\omega}$ semantics). For any model $\mathcal{M}$ and assignment function $g$ :

i. $\llbracket A \rrbracket^{g}=\llbracket A \rrbracket$

$$
=g(A)
$$

ii. $\llbracket \lambda u_{a}(B) \rrbracket^{g}(d) \doteq \llbracket B \rrbracket^{g[u / d]}$

iii. $\llbracket B A \rrbracket^{g} \doteq \llbracket B \rrbracket^{g}\left(\llbracket A \rrbracket^{g}\right)$

iv. $\llbracket A=B \rrbracket^{g}=1$

v. $\llbracket \neg \phi \rrbracket^{g} \doteq 1 \backslash \llbracket \phi \rrbracket^{g}$

$\llbracket \phi \rightarrow \psi \rrbracket^{g} \doteq 1 \backslash\left(\llbracket \phi \rrbracket^{g} \backslash \llbracket \psi \rrbracket^{g}\right)$

$\llbracket \phi \wedge \psi \rrbracket^{g} \doteq \llbracket \phi \rrbracket^{g} \cap \llbracket \psi \rrbracket^{g}$

$\llbracket \phi \vee \psi \rrbracket^{g} \doteq \llbracket \phi \rrbracket^{g} \cup \llbracket \psi \rrbracket^{g}$ if $A \in \operatorname{Con}_{a}$ if $A \in \operatorname{Var}_{a}$

if $d \in D_{a}$

iff $\llbracket A \rrbracket^{g}, \llbracket B \rrbracket^{g} \in D_{a} \& \llbracket A \rrbracket^{g}=\llbracket B \rrbracket^{g}$ 
vi. $\llbracket \forall u_{a} \phi \rrbracket^{g} \doteq \cap\left\{\llbracket \phi \rrbracket^{g[u / d]}: d \in D_{a}\right\}$

$\llbracket \exists u_{a} \phi \rrbracket^{g} \doteq \cup\left\{\llbracket \phi \rrbracket^{g[u / d]}: d \in D_{a}\right\}$

vii. $\llbracket u_{a}^{\top} \oplus B \rrbracket^{g} \doteq\left\langle\left(g\left(u_{a}\right) \oplus \top \llbracket B \rrbracket^{g}\right), \perp \llbracket B \rrbracket^{g}\right\rangle$

$\llbracket u_{a}{ }^{\perp} \oplus B \rrbracket^{g} \doteq\left\langle\top \llbracket B \rrbracket^{g},\left(g\left(u_{a}\right) \oplus \perp \llbracket B \rrbracket^{g}\right)\right\rangle$

viii. $\llbracket \top a_{n} \rrbracket^{g}(i) \doteq\left((\top i)_{a}\right)_{n}$

if $i \in D_{s}$ $\llbracket \perp a_{n} \rrbracket^{g}(i) \doteq\left((\perp i)_{a}\right)_{n}$

if $i \in D_{s}$

ix. $\llbracket A\{B\} \rrbracket^{g} \doteq x\left\{\llbracket A \rrbracket^{g}(j) \mid j \in\{\}\left[B \rrbracket^{g}\right\}\right.$

A default information state is assumed, defined in terms of a context of utterance. A context of utterance is modeled here as a pair of a non-empty set of worlds ( $p_{0}$, the initial context set) and the speaker, represented by the individual constant $\mathrm{i}$ and constrained by the predicate speak (type $\omega \delta t$ ). [For each world in (the set characterized by $\left.{ }^{\left({ }^{\{}\right)}\right)$) the context set ${ }^{\{\}} p_{0}$, $\llbracket i \rrbracket$ is in the set of individuals speaking in that world.] The $p_{0}$-default information state ${ }^{s t} p_{0}$ is (the characteristic function of $(x)$ ) the set of pairs of sequences of the form $\left\langle\left\langle w, p_{0}\right\rangle,\langle\rangle\right\rangle$ for each $w$ in the context set $p_{0}$. Thus, by default $p_{0}$ is the most prominent top proposition and each world in the context set is the local top world on some $T \perp$-list in ${ }^{s t} p_{0}$.

Definition 7 (contexts and defaults). For any model $\mathcal{M}$,

i. An $\mathcal{M}$-context is a pair $\left\langle p_{0}\right.$, $\left.\llbracket i \rrbracket\right\rangle \in D_{\omega t} \times D_{\delta}$ such that (a) ${ }^{\{\xi} p_{0} \neq \varnothing$ and (b) $\forall w \in{ }^{\{} p_{0}: \llbracket i \rrbracket \in\{\} \operatorname{speak} \rrbracket(w)$

ii. ${ }^{s t} p_{0}=x\left\{\left\langle\left\langle w, p_{0}\right\rangle,\langle\rangle\right\rangle \mid w \in{ }^{\{\}} p_{0}\right\}$ is the $p_{0}$-default (info-)state

Because the top sequence tracks the context set, and thus the truth conditional information contributed by a sentence, the definition of truth and falsity is sensitive to whether or not the context set has been updated by a term. In particular, it is sensitive to what the most prominent top objects are. The set of primary topics, for a term $\phi$ and input information state $c$, is the set of the most prominent top objects from all the $T \perp$-lists $j$, where $j$ is not in the input information state $c$ but is in the output state that results from updating $c$ with $\llbracket \phi \rrbracket$.

Definition 8 (primary topics). For any model $\mathcal{M}$, information state $c \in D_{s t}$, and $(s t) s t$ term $\phi$, the set of primary topics $\operatorname{TOP}_{\mathcal{M}, c} \phi$ is:

- $\operatorname{TOP}_{\mathscr{M}, c} \phi=\left\{(\top j)_{1} \mid j \in\left(D_{s} \backslash{ }^{\{\}} C\right) \& \forall g: j \in\{\}\left(c \llbracket \phi \rrbracket^{g}\right)\right\}$ 
Varieties of update

Truth values are only assigned to terms that update the primary topic to a (single) proposition ( $\operatorname{TOP}_{\mathcal{M}, c} \phi=\{p\}$ ). Thus, declarative sentences are assigned truth values while imperatives and interrogatives are not.

Definition 9 (truth and falsity). For any model $\mathcal{M}$, information state $c \in D_{s t}$, and $(s t) s t$ term $\phi$ :

i. $\phi$ is true relative to $\mathcal{M}$ and $c$ at world $w$

$$
\text { iff } \exists p \in D_{\omega t}: \operatorname{TOP}_{\mathcal{M}, c} \phi=\{p\} \& w \in{ }^{\{\}} p
$$

ii. $\phi$ is false relative to $\mathcal{M}$ and $c$ at world $w$

$$
\text { iff } \exists p \in D_{\omega t}: \operatorname{TOP}_{\mathscr{M}, c} \phi=\{p\} \& w \notin\left\{{ }^{\{\}}\right.
$$

An alternative way to define truth relative to just a model and world, independent of a particular information state, would be to treat the initial context set as the singleton set of that world and see if there is a non-empty output information state (adapting the definition of truth in Starr 2010).

\section{A.2 DRT-Style abbreviations for $\mathrm{UC}_{\omega}$-terms}

Static relations $(a \in \mathrm{DR}(\Theta))$

$\begin{array}{lll}A_{a} \in B_{a t} & \text { for } & B A \\ A_{a} \notin B_{a t} & \text { for } & \neg B A \\ A_{a t} \subseteq B_{a t} & \text { for } & \forall u_{a}(u \in A \rightarrow u \in B) \\ B\left(A_{1}, \ldots, A_{n}\right) & \text { for } & B A_{1} \ldots A_{n}\end{array}$

Local projections, conditions, and updates $(a \in \mathrm{DR}(\Theta), \mathbf{R} \in\{=, \in, \notin, \subseteq\})$

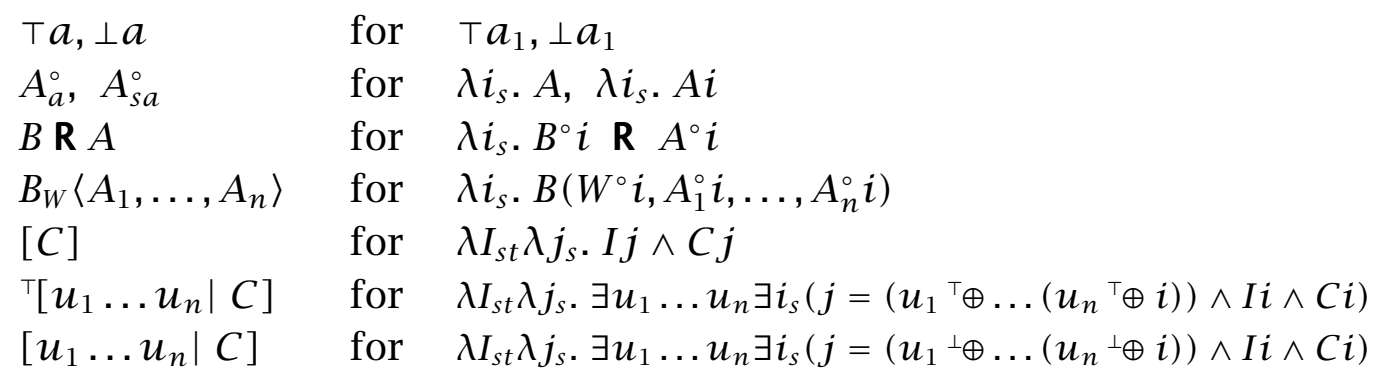

Global updates $(a \in \mathrm{DR}(\Theta), \mathbf{R} \in\{=, \in, \notin, \subseteq\})$

$\begin{array}{lll}{[A \mathbf{R} B \|]} & \text { for } & \lambda I_{s t} \lambda j_{s} . I j \wedge A j \mathbf{R} B\{I\} \\ {[A\|\mathbf{R} B\|]} & \text { for } & \lambda I_{s t} \lambda j_{s} . I j \wedge A\{I\} \mathbf{R} B\{I\} \\ { }^{\mathrm{T}}\left[u_{a} \mid u \mathbf{R} A \|\right] & \text { for } & \lambda I_{s t} \lambda j_{s} . \exists u_{a} \exists i_{s}\left(j=\left(u^{\top} \oplus i\right) \wedge I i \wedge u \mathbf{R} A\{I\}\right) \\ {\left[u_{a} \mid u \mathbf{R} A \|\right]} & \text { for } & \lambda I_{s t} \lambda j_{s} . \exists u_{a} \exists i_{s}\left(j=\left(u{ }^{\perp} \oplus i\right) \wedge I i \wedge u \mathbf{R} A\{I\}\right) \\ \left(J_{(s t) s t} ; K_{(s t) s t}\right) & \text { for } & \lambda I_{s t} \lambda j_{s} .(K(J I)) j\end{array}$




\section{A.3 Addition for analyzing interrogative mood}

In the analysis of interrogative mood, I use the update $\left[p \mid p \in{ }^{?} \perp \omega \|\right]$, but

? is not defined in $\mathrm{UC}_{\omega}$. Intuitively, it takes a global value of an anaphor (always a set) and gives back the set containing that value and its complement. However, because global updates are abbreviated above as a unit, to minimize changes to the above definitions, I take $\left[u_{a} \mid u \in{ }^{?} A \|\right]$ to abbreviate $\lambda I_{s t} \lambda j_{s} . \exists u_{a} \exists i_{s}\left(j=\left(u{ }^{\perp} \oplus i\right) \wedge I i \wedge(u=A\{I\} \vee u=\overline{A\{I\}})\right)$ where the complement of a global anaphor $\overline{A\{B\}} \in$ Term $_{a t}$ is interpreted as $\llbracket \overline{A_{s a}\{B\}} \rrbracket^{g} \doteq x\left(D_{a} \backslash\left\{\llbracket A \rrbracket^{g}(j) \mid j \in\{\} \llbracket B \rrbracket^{g}\right\}\right)$.

\section{References}

Amaral, Patricia, Craige Roberts \& E. Allyn Smith. 2007. Review of The logic of conventional implicatures by Chris Potts. Linguistics and Philosophy 30(6). 707-749. http://dx.doi.org/10.1007/s10988-008-9025-2.

AnderBois, Scott, Adrian Brasoveanu \& Robert Henderson. 2010. Crossing the appositive / at-issue meaning boundary. Semantics and Linguistic Theory (SALT) 20. 328-346. http://elanguage.net/journals/salt/article/view/20. 328.

Asher, Nicholas. 200o. Truth conditional discourse semantics for parentheticals. Journal of Semantics 17. 31-50. http://dx.doi.org/10.1093/jos/17.1.31. van den Berg, Martin. 1996. Some aspects of the internal structure of discourse. Amsterdam: ILLC, University of Amsterdam PhD thesis.

Bittner, Maria. 2009. Tense, mood, and centering. Ms., Rutgers University. http://www.rci.rutgers.edu/ mbittner/bittnero9_tmc.pdf.

Bittner, Maria. 2011. Time and modality without tenses or modals. In Renate Musan \& Monika Rathert (eds.), Tense across languages. Tübingen: de Gruyter.

Brasoveanu, Adrian. 2007. Structured nominal and modal reference. Rutgers University PhD thesis. http://people.ucsc.edu/ abrsvn/diss_brasoveanu_ 2007.pdf.

Brasoveanu, Adrian, Donka Farkas \& Floris Roelofsen. 2012. Polarity particles and the anatomy of n-words. Sinn und Bedeutung 16. 99-113.

Ciardelli, Ivano, Jeroen Groenendijk \& Floris Roelofsen. 20o9. Attention! 'might' in Inquisitive Semantics. Semantics and Linguistic Theory (SALT) 19. 91-108. http://elanguage.net/journals/salt/article/view/19.6. 
Varieties of update

Dekker, Paul. 1994. Predicate logic with anaphora. Semantics and Linguistic Theory (SALT) 4. 79-95. http://elanguage.net/journals/salt/article/view/ 4.79.

van Eijck, Jan. 2001. Incremental dynamics. Journal of Logic, Language, and Information 10(3). 319-351. http://dx.doi.org/10.1023/A:1011251627260.

van Eijck, Jan \& Rick Nouwen. 2002. Quantification and reference in incremental processing. Manuscript, Utrecht University. http://homepages.cwi. nl/ jve/papers/o2/qar/Qar.ps.

Faller, Martina. 2002. Semantics and pragmatics of evidentials in Cuzco Quechua. Stanford PhD thesis.

Faller, Martina. 2006. Evidentiality above and below speech acts. http:// semanticsarchive.net/Archive/GZiZjBhO/.

Farkas, Donka \& Kim Bruce. 2010. On reacting to assertions and polar questions. Journal of Semantics 27(1). 81-118. http://dx.doi.org/10.1093/jos/ ffporo.

von Fintel, Kai \& Anthony S. Gillies. 2007. An opinionated guide to epistemic modality. In Tamar Szabó Gendler \& John Hawthorne (eds.), Oxford studies in epistemology, vol. 2. Oxford University Press.

von Fintel, Kai \& Anthony S. Gillies. 2010. Must . . . stay . . . strong! Natural Language Semantics 18(4). 351-383. http://dx.doi.org/10.1007/s11050010-9058-2.

Fisher, Louise, Wayne Leman, Leroy Pine Sr. \& Marie Sanchez. 2006. Cheyenne dictionary. http://www.cdkc.edu/cheyennedictionary/index.html. Chief Dull Knife College.

Ginzburg, Jonathan. 1996. Interrogatives: Questions, facts, and dialogue. In Shalom Lappin (ed.), The handbook of contemporary semantic theory, 385-422. Oxford: Blackwell Publishers.

del Gobbo, Francesca. 2003. Appositives at the interface. University of California, Irvine $\mathrm{PhD}$ thesis.

del Gobbo, Francesca. 2007. On the syntax and semantics of appositive relative clauses. In Nicole Dehé \& Yordanka Kavalova (eds.), Parentheticals. John Benjamins.

Groenendijk, Jeroen. 1999. The logic of interrogation: Classical version. Semantics and Linguistic Theory (SALT) 9. 109-126. http://elanguage.net/ journals/salt/article/view/9.109.

Groenendijk, Jeroen \& Floris Roelofsen. 2009. Inquisitive semantics and pragmatics. In Jesus M. Larrazabal \& Larraitz Zubeldia (eds.), Meaning, content, and argument: proceedings of the ILCLI international workshop 
on semantics, pragmatics, and rhetoric, 41-72. University of the Basque Country Publication Service.

Groenendijk, Jeroen \& Martin Stokhof. 1984. Studies on the semantics of questions and the pragmatics of answers. University of Amsterdam PhD thesis. http://dare.uva.nl/en/record/123669.

Groenendijk, Jeroen \& Martin Stokhof. 1991. Dynamic predicate logic. Linguistics and Philosophy 14(1). 39-100. http://dx.doi.org/10.1007/BFoo628304. Grosz, Barbara J., Arivind Joshi \& Scott Weinstein. 1995. Centering: a framework for modeling the local coherence of discourse. Computational Linguistics 21(2). 203-225.

Gunlogson, Christine. 2001. True to form: rising and falling declaratives as questions in English. University of California, Santa Cruz PhD thesis.

Gunlogson, Christine. 2002. Declarative questions. Semantics and Linguistic Theory (SALT) 12. 124-143. http://elanguage.net/journals/salt/article/ view/12.124.

Hamblin, Charles. 1973. Questions in Montague English. Foundations of Language 10(1). 41-53. http://www.jstor.org/stable/25000703.

Hardt, Daniel. 1996. Centering in dynamic semantics. In, Proceedings of the 16th International Conference on Computational Linguistics (COLING 16), 519-524. International Committee on Computational Linguistics. Copenhagen: International Committee on Computational Linguistics.

Horn, Lawrence R. 2002. Assertoric inertia and NPI licensing. Chicago Linguistic Society (CLS) 38(2: The Panels). 55-82.

Jayez, Jacques \& Corinne Rossari. 2004. Parentheticals as conventional implicatures. In Francis Corblin \& Henriëtte de Swart (eds.), The handbook of French semantics. CSLI Publications.

Kamp, Hans. 1981. A theory of truth and semantic representation. In Jeroen A. Groenendijk, Theo Janssen \& Martin Stokhof (eds.), Formal methods in the study of language, 277-322. Dordrecht: Foris.

Kamp, Hans \& Uwe Reyle. 1993. From discourse to logic: introduction to modeltheoretic semantics in natural language, formal logic and discourse representation theory. Dordrecht: Kluwer Academic Publishers.

Karttunen, Lauri. 1976. Discourse referents. In John McCawley (ed.), Syntax and semantics 7, 363-385. New York: Academic Press.

Koev, Todor. 2012. On the information status of appositive relative clauses. In Maria Aloni, Vadim Kimmelman, Floris Roelofsen, Galit Weidman Sassoon, Katrin Schulz \& Matthijs Westera (eds.), Logic, language and meaning: proceedings of the 18th Amsterdam Colloquium (2011), 401-410. Springer. 
Varieties of update

Kratzer, Angelika. 1991. Modality. In Arnim von Stechow \& Dieter Wunderlich (eds.), Semantics: an international handbook of contemporary research, 639-650. Berlin: de Gruyter.

Lee, Jungmee. 2011. Evidentiality and its interaction with tense: evidence from Korean. The Ohio State University PhD thesis.

Leman, Wayne. 1980a. A reference grammar of the Cheyenne language (Occasional Publications in Anthropology, Series No. 5). Greely, Colorado: Museum of Anthropology, University of Northern Colorado.

Leman, Wayne (ed.). Cheyenne texts: an introduction to Cheyenne literature (Occasional Publications in Anthropology, Series No. 6). Greeley, Colorado: Museum of Anthropology, University of Northern Colorado.

Leman, Wayne (ed.). Náéváhóó' óhtséme / We are going back home: Cheyenne history and stories told by James Shoulderblade and others (Memoir 4). Winnipeg: Algonquian \& Iroquoian Linguistics.

Leman, Wayne. 2012. A reference grammar of the Cheyenne language. Updated version of Leman 1980a. Raleigh, North Carolina: Lulu Press.

Lewis, David K. 1979. Scorekeeping in a language game. Journal of Philosophical Logic 8(3). 339-359. http://dx.doi.org/10.1007/BFo0258436.

Matthewson, Lisa, Hotze Rullmann \& Henry Davis. 2007. Evidentials as epistemic modals: evidence from St'át'imcets. In Jeroen Van Craenenbroeck (ed.), Linguistic variation yearbook 2007, vol. 7. John Benjamins.

McCready, Eric. 2008. What man does. Linguistics and Philosophy 31(6). 671724. http://dx.doi.org/10.1007/s10988-009-9052-7.

McCready, Eric. 2010. Varieties of conventional implicature. Semantics and Pragmatics 3(8). 1-57. http://dx.doi.org/10.3765/sp.3.8.

Murray, Sarah E. 2009. A Hamblin semantics for evidentials. Semantics and Linguistic Theory (SALT) 19. 324-341. http://www.semanticsarchive.net/ Archive/2I5ZjdmY/.

Murray, Sarah E. 2010. Evidentiality and the structure of speech acts. Rutgers University PhD thesis. http://www.semanticsarchive.net/Archive/ WViOGQxY/.

Muskens, Reinhard. 1995. Tense and the logic of change. In Urs Egli, Peter E. Pause, Christoph Schwarze, Arnim von Stechow \& Götz Wienold (eds.), Lexical knowledge in the organization of language, 147-184. New York: John Benjamins.

Muskens, Reinhard. 1996. Combining Montague semantics and discourse representation. Linguistics and Philosophy 19(2). 143-186. http://dx.doi. org/10.1007/BFoo635836. 
Nouwen, Rick. 2007. On appositives and dynamic binding. Journal of Language and Computation 5(1). 87-102. http://dx.doi.org/10.1007/s11168oo6-9019-6.

Portner, Paul. 2004. The semantics of imperatives within a theory of clause types. Semantics and Linguistic Theory (SALT) 14. http://elanguage.net/ journals/salt/article/view/14.235.

Potts, Christopher. 2005. The logic of conventional implicatures (Oxford Studies in Theoretical Linguistics). Oxford: Oxford University Press.

Roberts, Craige. 1989. Modal subordination and pronominal anaphora in discourse. Linguistics and Philosophy 12(6). 683-721. http://dx.doi.org/10. 1007/BFoo632602.

Roberts, Craige. 1996. Information Structure in Discourse: Towards an Integrated Formal Theory of Pragmatics. Tech. rep. OSU Working Papers in Linguistics, volume 49, Jae-Hak Yoon and Andreas Kathol, editors. Columbus, Ohio: Linguistics Department, The Ohio State University.

Ross, John Robert. 1973. Slifting. In Maurice Gross, Morris Halle \& Marcel-Paul Schützenberger (eds.), The formal analysis of natural languages, 133-169. The Hague: Mouton.

Schlenker, Philippe. 2010. Supplements within a unidimensional semantics I: scope. In Maria Aloni, Harald Bastiaanse, Tikitu de Jager \& Katrin Schulz (eds.), Logic, language and meaning: proceedings of the 17th Amsterdam colloquium (2009), 74-83. Berlin, Heidelberg: Springer.

Shanon, Benny. 1976. On the two kinds of presuppositions in natural language. Foundations of Language 14. 247-249. http://www.jstor.org/ stable/25170057.

Simons, Mandy. 2007. Observations on embedding verbs, evidentiality, and presupposition. Lingua 117(6). 1034-1056. http://dx.doi.org/10.1016/j. lingua.2006.05.006.

Simons, Mandy, Judith Tonhauser, David Beaver \& Craige Roberts. 2010. What projects and why. Semantics and Linguistic Theory (SALT) 20. 309-327. http://elanguage.net/journals/salt/article/view/20.309.

Slote, Michael A. 1979. Assertion and belief. In Jonathan Dancy (ed.), Papers on language and logic, 177-90. Keele, England: Keele University Library.

Stalnaker, Robert C. 1975. Indicative conditionals. Philosophia 5. 269-286.

Stalnaker, Robert C. 1978. Assertion. In Peter Cole (ed.), Syntax and semantics 9: pragmatics, 315-332. New York: Academic Press.

Starr, William B. 2010. Conditionals, meaning and mood. Rutgers University PhD thesis. http://williamstarr.net/. 
Varieties of update

Stone, Matthew. 1994. The Reference argument of epistemic must. In Harry Bunt, Reinhard Muskens \& Gerrit Rentier (eds.), Proceedings of the First International Workshop on Computational Semantics (IWCS-1), 181-190. ITK, Tilburg University.

Stone, Matthew. 1997. The Anaphoric Parallel between Modality and Tense. Tech. rep. 97-o6. University of Pennsylvania Institute for Research in Cognitive Science.

Stone, Matthew. 1999. Reference to Possible Worlds. Tech. rep. 49. Update of Stone (1997). Rutgers University Center for Cognitive Science.

Stone, Matthew \& Daniel Hardt. 1999. Dynamic discourse referents for tense and modals. In Harry Bunt \& Reinhard Muskens (eds.), Computing meaning, vol. 2, 302-321. Dordrecht: Kluwer. http://dx.doi.org/10.1007/978-94O11-4231-1_15.

Tonhauser, Judith. 2012. Diagnosing (not-)at-issue content. In Elizabeth BogalAllbritten (ed.), Proceedings of the Sixth Conference on the Semantics of Under-represented Languages in the Americas and SULA-bar. Amherst, MA: GLSA Publications.

Veltman, Frank. 1996. Defaults in update semantics. Journal of Philosophical Logic 25(3). 221-261. http://dx.doi.org/10.1007/BFoo248150.

Vermeulen, Cees F.M. 1993. Sequence semantics for dynamic predicate logic. Journal of Logic, Language, and Information 2(3). 217-254. http://dx.doi. org/10.1007/BFo1050788.

Sarah E. Murray

Department of Linguistics

212 Morrill Hall

Cornell University

Ithaca, NY 14853

sarah.murray@cornell.edu 